Atmos. Chem. Phys. Discuss., 8, 16027-16059, 2008 www.atmos-chem-phys-discuss.net/8/16027/2008/ (C) Author(s) 2008. This work is distributed under the Creative Commons Attribution 3.0 License. and Physics $(A C P)$. Please refer to the corresponding final paper in $A C P$ if available.

\title{
Global error maps of aerosol optical properties: an error propagation analysis
}

\section{K. Tsigaridis ${ }^{1,{ }^{*}}$, Y. Balkanski ${ }^{1}$, M. Schulz $^{1}$, and A. Benedetti ${ }^{2}$}

${ }^{1}$ Lab. des Sciences du Climat et de l'Environnement (LSCE), 91191 Gif-sur-Yvette, France

${ }^{2}$ European Center for Medium Range Weather Forecasts (ECMWF), Reading, UK now at: NASA Goddard Institute for Space Studies (GISS), 2880 Broadway, NY 10025, USA

Received: 1 August 2008 - Accepted: 1 August 2008 - Published: 22 August 2008

Correspondence to: K. Tsigaridis (ktsigaridis@giss.nasa.gov)

Published by Copernicus Publications on behalf of the European Geosciences Union.

\section{ACPD}

8, 16027-16059, 2008

Global error maps of aerosol optical properties

K. Tsigaridis et al.

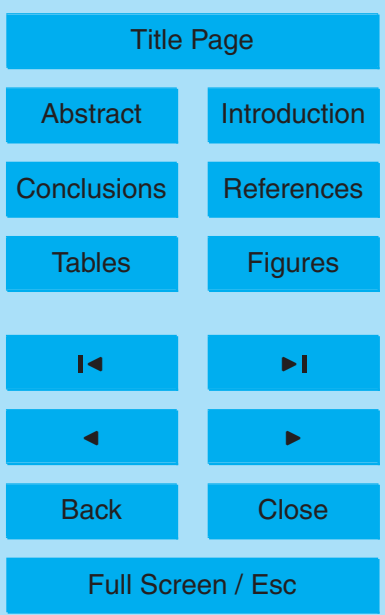

Printer-friendly Version

Interactive Discussion 


\section{Abstract}

Among the numerous atmospheric constituents, aerosols play a unique role on climate, due to their scattering and absorbing capabilities, visibility degradation and their effect on incoming and outgoing radiation. The most important optical properties are 5 the aerosol optical depth (AOD), the asymmetry parameter $(g)$ and the single scattering albedo (SSA). Uncertainties in aerosol microphysics in global models, which in turn affect their optical properties, propagate to uncertainties on the effect of aerosols on climate. This study aims to estimate the uncertainty of AOD, $g$ and SSA attributable to the aerosol representation in models, namely mixing state, aerosol size and aerosol associated water. As a reference, the monthly mean output of the general circulation model LMDz-INCA from the international comparison exercise AEROCOM B was used. For the optical properties calculations, aerosols were considered either externally mixed, homogeneously internally mixed or coated spheres. The radius was allowed to vary by $\pm 20 \%$ (with $2 \%$ intervals) and the aerosol water content by $\pm 50 \%$ (with $5 \%$ intervals)

15 with respect to the reference model output. All of these possible combinations were assumed to be equally likely and the optical properties were calculated for each one of them. A probability density function (PDF) was constructed at each model grid point for AOD, $g$ and SSA. From this PDF, the $1 \sigma$ and $2 \sigma$ uncertainties of the AOD, $g$ and SSA were calculated and are available as global maps for each month. For the range of the cases studied, we derive a maximum $2 \sigma$ uncertainty range in AOD of $70 \%$, while for $g$ and SSA the maxima reach $18 \%$ and $28 \%$ respectively. The mixing state was calculated to be important, with the aerosol absorption and SSA being the most affected properties when absorbing aerosols are present.

\section{Introduction}

25 Aerosols are ubiquitous atmospheric components that can play multiple roles on climate: they can absorb or scatter solar radiation (direct effect), modify the cloud prop-
Global error maps of aerosol optical properties

K. Tsigaridis et al.

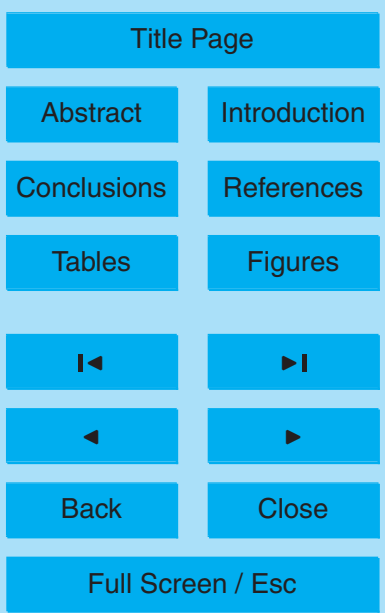

Printer-friendly Version

Interactive Discussion 
erties and precipitation frequency and intensity (indirect effect) and act as surfaces for heterogeneous reactions, altering the gas-phase chemical composition of the atmosphere. Quantifying their role on these effects is an ongoing challenging issue.

In order to calculate the amount of solar radiation that particles can scatter and/or 5 absorb, it is essential to know a number of parameters concerning their physical and chemical properties. These include the shape and size of aerosols, their mixing state, the dry aerosol composition and the mass of the aerosol associated water. All these parameters, which change in space and time, interact with the radiation field and increase the complexity of the calculation of the aerosol effect on climate. When absorbing com10 ponents are present, the state of mixing can affect considerably both the aerosol absorption and the single scattering albedo (SSA), which determines how much of the total light extinction of particles is due to scattering. The aerosol size alters the asymmetry parameter $(g)$ which is a bulk measure of the scattered light direction compared to the incident radiation direction. Large particles scatter solar radiation less efficiently and to a larger portion in the forward direction when compared with smaller ones.

Global models do not agree on the detail for the aerosol microphysical parameterizations, but should be able to simulate their chemical composition and prognostically determine the mixing state and the size of aerosols in space and time (Textor et al., 2006). Many models consider that the aerosols are externally mixed (each single aerosol particle consists of a single chemical component) while the more sophisticated ones consider internally mixed particles, with the various components being homogeneously mixed. Very few models assume that $\mathrm{BC}$ is always an inner core of soluble material (Lesins et al., 2002; Stier et al., 2005; Jacobson et al., 2007). Note that the mixing state also affects the lifetime of aerosols (e.g. due to change in aerosol hygroscopicity). Motivated by these findings, one goal of the present study is to quantify how the different approaches that are used to represent the aerosol mixing state affect the aerosol optical properties.

Several factors influence the direct effect of aerosols on climate. Liu et al. (2007) calculated a $10 \%$ variation on the global AOD $(0.120-0.131)$ by varying only the mete-

\section{Global error maps of aerosol optical properties}

K. Tsigaridis et al.

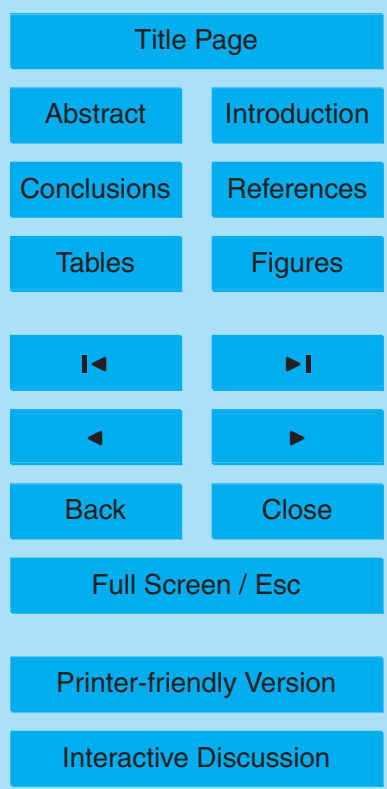

\section{9}


orology of the model, which affected the transport, removal and, hence, the lifetime of aerosols. Other important parameters are the uncertainty in aerosol size and aerosol water content (which is affected by the aerosol hygroscopicity). These are not well quantified but play a major role in calculating both the AOD and the radiative forcing of

5 aerosols. For this reason, the second goal of this work is to document the combined optical properties uncertainty resulting from our poor knowledge of the mixing state and the uncertainty of the dry aerosol size and water content.

The two goals were achieved by an error propagation analysis, based on the output of the general circulation model LMDz-INCA (which is one of the models participating 10 in the AEROCOM intercomparison exercise; http://nansen.jpsl.jussieu.fr/AEROCOM/). The error propagation analysis was performed as follows: the LMDz-INCA model output was perturbed within a reasonable range for the aerosol size and water content and the effect of this disturbance to the aerosol optical properties was calculated. The estimated uncertainty, which is based on the distribution of the calculated optical properties of all perturbed cases, provides information on where the accurate knowledge of the aerosol composition, size and state of mixing is important and highlights the regions in which more studies are needed. At a later stage, the mapped uncertainty estimates will be used as an a priori model error for use in the European Centre for Medium-Range Weather Forecasts (ECMWF) aerosol assimilation system, as part of the EU-funded project Global and regional Earth-system Monitoring using Satellite and in-situ data (GEMS; http://gems.ecmwf.int/). It has to be noted that the error calculated by the present work is not the full uncertainty on the optical properties of a given model simulation on a given day, since it is based on monthly mean reference fields. Further, since it uses the output of a particular model (LMDz-INCA) as reference, it is expected to contain a systematic bias characteristic to that model.

In order to calculate the optical properties of pure aerosol components, we neglected the role of the shape of the particles, by assuming that these are spherical; we then applied the Mie theory. This assumption is valid for most aged aerosols, but freshly emitted and some natural particles can deviate considerably from sphericity (Reid et

Global error maps of aerosol optical properties

K. Tsigaridis et al.

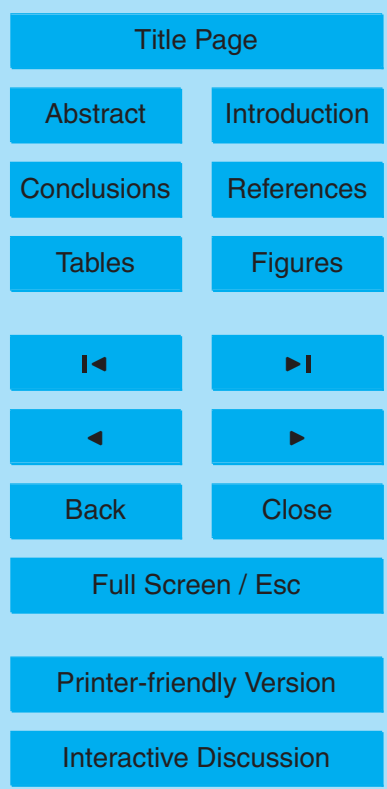

16030 
al., 2005b). Very close to intense fire sources, non spherical particles are expected to have more or less conserved extinction efficiency when compared to spherical ones, but the scattering is expected to be increased compared to absorption, together with an increase in $g$ (Reid et al., 2005a). Nevertheless, most (but not all) submicron parti5 cles are spherical (McMurry, 2000). Kahnert et al. (2007) calculated that neglecting the non-spherical nature of mineral aerosols is a major source of error, contrary to common beliefs. However, the optical calculations for non-spherical aerosols are extremely complex and beyond the scope of this paper.

\section{Methodology}

10 In the present study, all calculations were performed at the wavelength of $550 \mathrm{~nm}$. Nevertheless, similar calculations could be performed for any wavelength for which the refractive indices of the individual components are known. Similarly, the range of cases selected here can be easily narrowed down or expanded. The refractive indices of the pure components used in this study are presented in Table 1 together with the densities adopted for the individual aerosol components. As already mentioned, all calculations assume that the particles are spherical.

We assumed two modes of aerosol sizes: accumulation and coarse. For both, we assumed that the aerosol population is lognormally distributed, with a lognormal distribution standard deviation sigma $(\sigma)$ of 1.59 for the accumulation mode and 2.0 for the coarse mode. For the calculations, the monthly mean aerosol mass and number temporal and spatial distribution calculated by the general circulation model LMDz-INCA (Hourdin and Armengaud, 1999; Hauglustaine et al., 2004; Schulz et al., 2006; Textor et al., 2006) for the year 2000 was used, which was identical with the AEROCOM experiment B, described by Textor et al. (2006) and Schulz et al. (2006). The aerosol species considered are the ones included in the LMDz-INCA model, namely: black carbon $(\mathrm{BC})$, organic carbon $(\mathrm{OC})$, sulfate $\left(\mathrm{SO}_{4}\right)$, sea-salt, dust and aerosol associated water $\left(\mathrm{H}_{2} \mathrm{O}\right)$. $\mathrm{BC}, \mathrm{OC}$ and $\mathrm{SO}_{4}$ are always in the accumulation mode, dust is always in

Global error maps of aerosol optical properties

K. Tsigaridis et al.

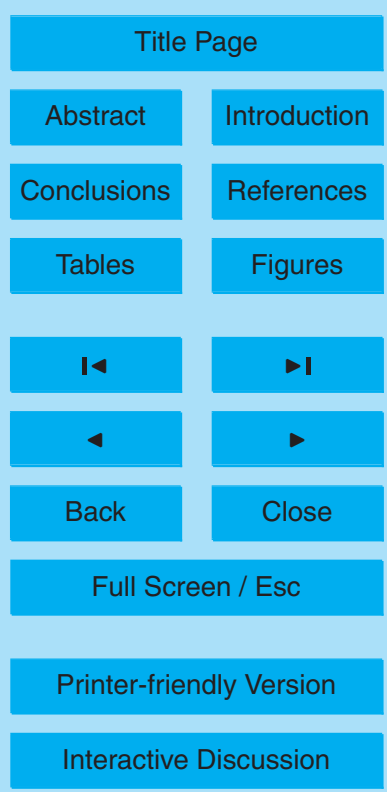

Interactive Discussion 
the coarse mode, while sea-salt and $\mathrm{H}_{2} \mathrm{O}$ can be in both.

\subsection{Optical calculations}

The relative size of the particles compared to the incident light wavelength, which is needed for the optical calculations instead of the absolute size and wavelength, is 5 expressed by the size parameter $x$ :

$x=\frac{2 \pi r}{\lambda}$

where $r$ is the aerosol radius $(m)$ and $\lambda$ is the wavelength of the incident light $(m)$. The maximum light scattering is for particles with similar circumference size $(x=1)$ as the incident light wavelength (550 $\mathrm{nm}$ in the present study), meaning that the maximum extinction is expected to occur by particles with size of about $100 \mathrm{~nm}$ radius.

The mass-based specific extinction coefficient $b_{\text {ext }}\left(\mathrm{m}^{2} \mathrm{~g}^{-1}\right)$ is a measure of attenuation of the light passing through the atmosphere due to the scattering and absorption by aerosol particles. It is calculated using the following equation:

$b_{\mathrm{ext}}=\frac{3 q_{\mathrm{ext}}}{4 \rho r_{\mathrm{eff}}}$

15 where $q_{\text {ext }}$ is the specific extinction efficiency (dimensionless) of the mixed aerosol and is computed by performing Mie calculations over the whole size range of the lognormal distribution, $\rho$ is the aerosol density $\left(\mathrm{g} \mathrm{m}^{-3}\right.$, Table 1$)$ and $r_{\text {eff }}$ the effective radius of the aerosol lognormal distribution $(m)$, defined as

$r_{\text {eff }}=\frac{\int r^{2} n(r) r d r}{\int r^{2} n(r) d r}$

20 where $r$ is the monodisperse particle radius $(\mathrm{m})$. The integration to compute $r_{\text {eff }}$ is done over the whole lognormal size distribution range. The same equation applies for

Global error maps of aerosol optical properties

K. Tsigaridis et al.

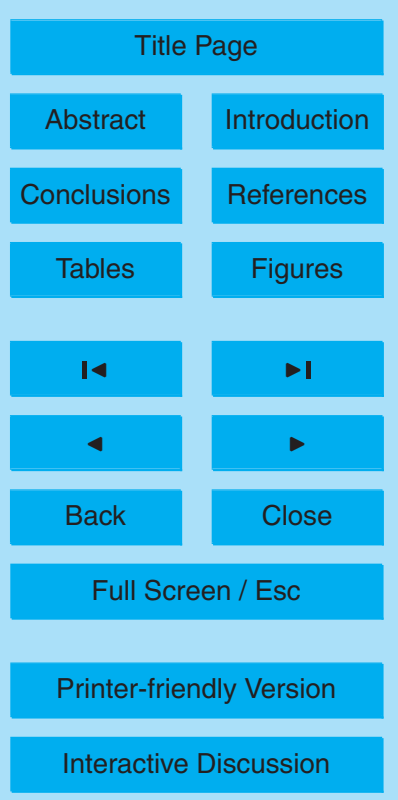

Interactive Discussion 
the mass-based specific scattering coefficient $b_{\text {sca }}$ when the specific scattering efficiency $q_{\text {sca }}$ is computed by performing Mie calculations, while the specific absorption efficiency $q_{\mathrm{abs}}$ and the mass-based specific absorption coefficient $b_{\mathrm{abs}}$ are defined by the following equations:

$5 \quad q_{\mathrm{abs}}=q_{\mathrm{ext}}-q_{\mathrm{sca}}$

$b_{\text {abs }}=b_{\text {ext }}-b_{\text {sca }}$

The optical properties studied in the present work are the AOD, the $g$ and the SSA. The AOD ( $\tau$; dimensionless) is a measure of the transparency of the atmosphere and is defined as the fraction of radiation that is scattered and/or absorbed in a path, in our case from the top of the atmosphere to the surface. It can be calculated by:

$\tau=b_{\text {ext }} M$

where $M$ is the total aerosol mass in the column $\left(\mathrm{g} \mathrm{m}^{-2}\right)$.

For the case of $g$, which is the average cosine of the scattering angle weighted by the intensity of the scattered light as a function of the angle, the equation of d'Almeida et al. (1991) is used to go from $g_{i}$ of a monodisperse aerosol population in a size bin computed by performing Mie calculations, to $g$ that represents the lognormal aerosol size distribution:

$$
g=\frac{\sum_{i} g_{i} q_{\mathrm{sca}, i}}{\sum_{i} q_{\mathrm{sca}, i}}
$$

where the subscript $i$ indicates the aerosol size bin. The value of $g$ ranges between

-1 for entirely backscattered light to +1 for entirely forward scattered light.

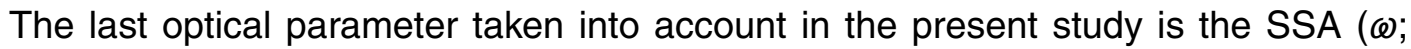
dimensionless), which is the ratio of the scattering over the total extinction by an aerosol population and is calculated by:

$\omega=\frac{b_{\mathrm{sca}}}{b_{\mathrm{ext}}}$

\section{Global error maps of aerosol optical properties}

K. Tsigaridis et al.

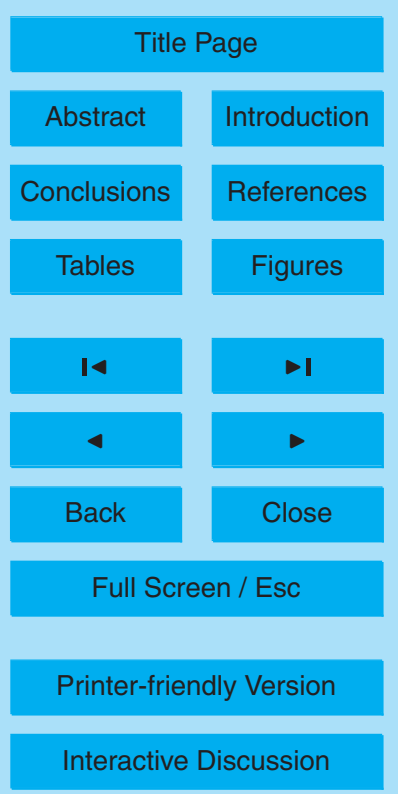


The range of SSA goes from zero for $100 \%$ absorbing aerosols, to one for completely scattering ones.

The calculations of $q_{\mathrm{ext}}, q_{\mathrm{sca}}, b_{\mathrm{ext}}, b_{\mathrm{sca}}$ and $g$ were performed for all possible aerosol mixtures, with each of the components able to vary from $0 \%$ to $100 \%$ per volume with

5 a step of $2 \%$, and for all possible aerosol sizes from $10 \mathrm{~nm}$ to $10 \mu \mathrm{m}$; the results were stored in a lookup table. By using this approach, the computationally expensive Mie calculations were performed only once per aerosol composition, aerosol size and state of mixing, while the lookup table remains available for future calculations. From the lookup table values, the values of $q_{\mathrm{abs}}, b_{\mathrm{abs}}$ and $\omega$ can be directly calculated by using the Eqs. (4), (5) and (8) respectively.

\subsection{Aerosol mixing}

The Mie calculations were performed for three different aerosol mixing states: external mixture, homogeneous internal mixture and inhomogeneous internal mixture, where black carbon is assumed to be the hydrophobic core lying at the center of the particle 5 and the rest of the aerosol components are forming a homogeneously mixed shell; the latter particles are referred to as concentric spheres. For the first two mixing states (external and homogeneous internal) the Bohren and Huffman (1983) Mie calculations method was applied. For the coated BC particles the concentric spheres Toon and Ackerman (1981) method was used, which converges to the results of Bohren and 20 Huffman (1983) for the cases where BC approaches both $0 \%$ (homogeneously mixed particles with no BC) and $100 \%$ (pure BC particles). When assuming externally mixed aerosols, the refractive indices of the pure components can be directly introduced in the Mie calculations, and the same can be done for the core of the concentric sphere particles which consist of pure BC. For the homogeneous internally mixed aerosols, as well as for the homogeneous shell of the concentric sphere particles, volume-weighted mixing of the single components refractive indices was applied. It should be noted that this approach, although widely used, has no physical meaning and is expected to overestimate the real particle absorption (Bond et al., 2006). The maximum error

Global error maps of aerosol optical properties

K. Tsigaridis et al.

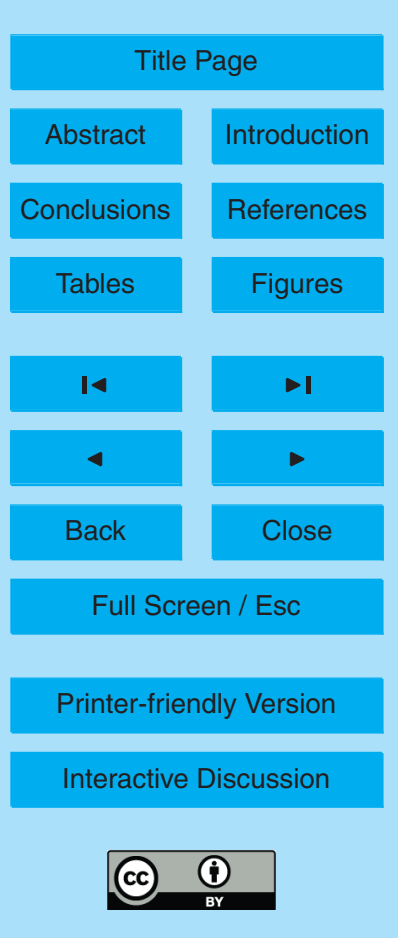


associated with the volume-weighted mixing of the refractive indices is less than $0.5 \%$ for the real part and up to 15\% for the imaginary part, which affects absorption (Lesins et al., 2002). The assumption of the concentric aerosol instead of the arbitrary-placed core anywhere within the volume of the particle can lead to small overestimations of 5 the particle absorption on the order of 15\% (Fuller et al., 1999).

The variation of the mixing state in our error propagation study has been done within the limits which are described hereafter. Naturally, accumulation and coarse mode particles are externally mixed. However, within the accumulation mode and for a given aerosol size distribution, $\mathrm{BC}, \mathrm{OC}, \mathrm{SO}_{4}$, sea-salt and $\mathrm{H}_{2} \mathrm{O}$ can be either externally mixed 10 (assuming that all pure component particles have the same size), or internally mixed, homogeneously or not. We assume that the possible homogeneous mixtures can be BC, OC, $\mathrm{SO}_{4}$ with $\mathrm{H}_{2} \mathrm{O}$, or sea-salt, $\mathrm{SO}_{4}$ with $\mathrm{H}_{2} \mathrm{O}$, since in the real atmosphere seasalt probably does not mix with $\mathrm{BC}$ (Moteki et al., 2007). We arbitrarily assumed that $\mathrm{SO}_{4}$ will be mixed with $\mathrm{BC}$ when sea-salt is less than $20 \%$ per volume, otherwise it will 15 mix with sea-salt. When sea-salt mixed particles coexist with $\mathrm{BC}$ mixed aerosol, the internally mixed $\mathrm{BC} / \mathrm{OC} / \mathrm{SO}_{4} / \mathrm{H}_{2} \mathrm{O}$ aerosols are assumed to be externally mixed with the internally mixed sea-salt/ $\mathrm{SO}_{4} / \mathrm{H}_{2} \mathrm{O}$ particles. Note that $\mathrm{SO}_{4}$ will be only in one of the two aerosol types, depending on sea-salt availability (Fig. 1a). When the concentric sphere model is used, particles are still assumed to be homogeneous by default, unless more than $1 \% \mathrm{BC}$ is present per volume; if this is the case, $\mathrm{BC}$ serves as the particle core with the other components $\left(\mathrm{OC}, \mathrm{SO}_{4}\right.$ and $\left.\mathrm{H}_{2} \mathrm{O}\right)$ composing the homogeneously mixed shell. For simplicity we assumed that both hydrophobic and hydrophilic BC (existent as separate tracers in INCA model) will reside together in the particle core, while hydrophobic and hydrophilic OC will always be together in the particle shell. Particles containing sea-salt are considered internally and homogeneously mixed, but always externally mixed with the ones containing BC. The aerosol mixing for accumulation mode aerosols is schematically presented in Fig. 1a.

For the case of coarse aerosols, the picture is clearer: dust and sea-salt most likely do not mix to an important degree in the real atmosphere, thus we assumed

Global error maps of aerosol optical properties

K. Tsigaridis et al.

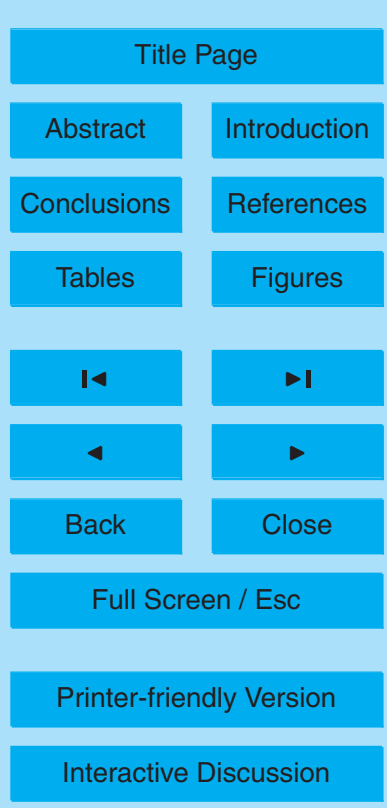


that they will remain always externally mixed, in line with field observations of freshly emitted aerosols (e.g. Song et al., 2005). This might not be the case though after long range transport (Song and Carmichael, 1999). Further, water is not mixing with dust, since dust is assumed to stay always in the hydrophobic mode in the LMDz-INCA

5 model. Although it is known that after cloud-processing the hygroscopic properties of aerosols will be altered, we do not account for this change in hygroscopicity in this study. The only hydrophilic component of the coarse mode in LMDz-INCA is sea-salt, which means that water can only coincide with sea-salt. The aerosol mixing for coarse mode aerosols is schematically presented in Fig. $1 \mathrm{~b}$.

10 Concerning the reference aerosol water content, the total water volume present on particles is calculated as the difference between the wet radius and the dry radius of the particles, separately for accumulation and coarse mode, based on the LMDzINCA results for the homogeneously mixed aerosols. This volume is then associated with the different aerosol components and mixtures presented in Fig. 1 by distributing 15 the total aerosol water on the different aerosol particles based on their hygroscopic properties, which depend on their dry composition. Since sea-salt is more hygroscopic than $\mathrm{BC}$ and $\mathrm{OC}$, and since $\mathrm{SO}_{4}$ will be either attached to the $\mathrm{BC} / \mathrm{OC}$ mixture or to sea-salt, the amount of water which will be present with the $\mathrm{BC} / \mathrm{OC} / \mathrm{SO}_{4}$ mixtures will differ with the one present with the sea-salt/ $\mathrm{SO}_{4}$ mixtures. This leads to externally mixed accumulation mode aerosols with different wet radii for the AOD calculations, dependent on their dry aerosol composition, although the INCA model computes only one mode radius for the accumulation mode.

\subsection{Uncertainty calculations}

The chemical composition of aerosols together with their size and water content are 25 the main parameters needed for the calculation of the aerosol optical properties. Models that include these calculations have significant uncertainties which are associated with all three parameters, including the mixing state of aerosols which is both uncertain and variable with time. In order to find the uncertainty range of the AOD, $g$ and SSA,

Global error maps of aerosol optical properties

K. Tsigaridis et al.

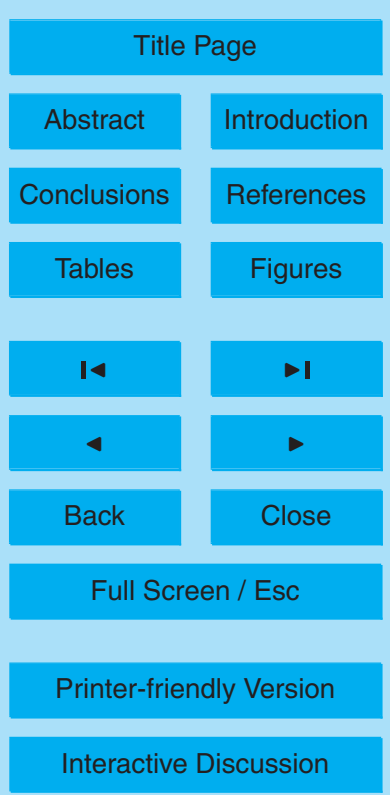


their values were calculated for a series of cases, based on certain assumptions on the aerosol mixing state, aerosol size and aerosol associated water, as described below. As a first step, the case with homogeneously internally mixed aerosols with aerosol size and water content taken from the monthly mean output of the LMDz-INCA model was 5 selected as a reference case, as described by the AEROCOM B experiment (Textor et al., 2006; Schulz et al., 2006). This case was chosen as the one closest to the original LMDz-INCA calculations and was used as a base when perturbing the aerosol properties for the uncertainty calculation studies. The second step was to create a range of cases, with the aerosol properties from the reference case perturbed by a certain 10 amount, and then calculate the AOD, $g$ and SSA. Having calculated the optical properties of all possible perturbed cases and their possible combinations, we constructed a probability density function (PDF) from the calculated AOD, $g$ and SSA values. These cases were constructed as the combination of the following three properties under examination, which were perturbed with respect to the reference case through a spectrum of possible values:

- Mixing state. AOD, $g$ and SSA were calculated for externally mixed aerosols, homogeneously internally mixed and concentric spheres (3 equally probable cases).

- Aerosol radius. The model calculated aerosol radius was allowed to vary by $\pm 20 \%$ from the reference case with steps of $2 \%$ ( 21 equally probable cases). This range can be much higher though, considering that the models participated in the AEROCOM intercomparison have a much larger spread on aerosol size representation, when using the same aerosol sources (Textor et al., 2006).

- Aerosol water. The uncertainty in aerosol water volume was allowed to vary by $\pm 50 \%$ from the reference case with steps of $5 \%$ ( 21 equally probable cases). This is a very conservative range, considering that Textor et al. (2006) found that the total aerosol water mass calculated from 11 different models spans through a vast range with standard deviation of $330 \%$.

Global error maps of aerosol optical properties

K. Tsigaridis et al.

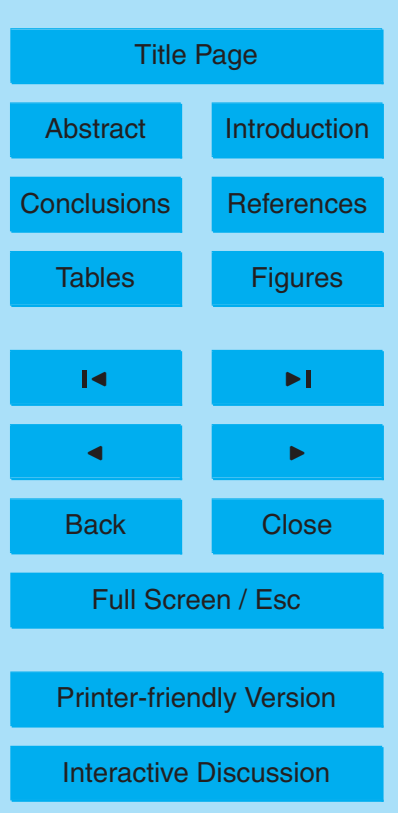

Interactive Discussion 
The above mentioned perturbances on aerosol representation were done for the accumulation and coarse mode aerosols simultaneously, meaning that the perturbance of e.g. the radius by a certain amount was applicable at the same time to both modes. After having calculated the AOD, $g$ and SSA for all these cases, together with all their

5 possible combinations $(3 \times 21 \times 21=1323$ combined cases $)$, a PDF was calculated for each one of the optical properties under consideration. This was done separately for each gridbox of the LMDz-INCA model, resulting in a temporally (monthly) and spatially (based on the model resolution) variable uncertainty.

We calculated per-gridbox and per-month both the 1-sigma and 2-sigma uncertain10 ties of AOD, $g$ and SSA, as the range within which $68.2 \%$ and $95.4 \%$ of the cases are found, respectively. We then calculated the mean and median values, and report them here together with the reference value and the 1- and 2-sigma uncertainty ranges. These statistics are also available as NetCDF files (http://www-Iscedods.cea. fr/aerocom/AOD_UNCERTAINTY_MAPS/).

\section{Results}

For the interpretation of the results, the reader should keep in mind that all discussions concerning aerosol size are referring to polydisperse lognormal distributions and all calculations are for $550 \mathrm{~nm}$ incident light wavelength. The accumulation mode particles have a narrower lognormal distribution, i.e. more single particles have a radius close 20 to the modal radius, due to the assumption of a lower standard deviation compared to the coarse mode (Sect. 2).

For the calculation of the optical properties of both the single component particles and the externally mixed aerosols, the optical properties of the pure substances need to be calculated. These are presented in the next section, followed by the results obtained for an aerosol population mixture rich in $\mathrm{BC}$ with varying mixing state. The mass-based extinction coefficient (needed for the AOD calculation), the mass-based scattering and absorption coefficients, together with the $g$ and SSA, are presented as

Global error maps of aerosol optical properties

K. Tsigaridis et al.

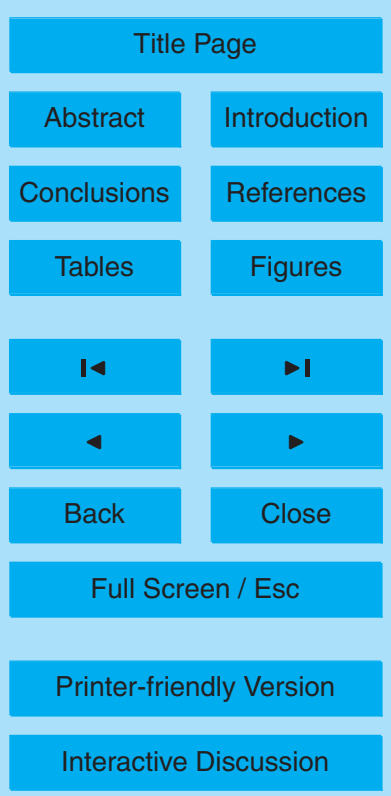


a function of the number median radius of the aerosol lognormal distribution.

\subsection{Single component optical properties}

Figure $2 \mathrm{a}-\mathrm{c}$ presents the Mie calculation results obtained for the specific extinction, scattering and absorption coefficients at $550 \mathrm{~nm}$. At small number median radii BC 5 absorption contributes strongly to the total BC extinction, while for a larger number median radii (roughly above $0.1-0.2 \mu \mathrm{m}$ ), scattering of light is the main contributor to $\mathrm{BC}$ aerosol extinction as absorption decreases. The rest of the components are either weak absorbers and do not extinct light as efficiently as BC (OC and dust) or do not absorb light causing less extinction than $\mathrm{BC}\left(\mathrm{SO}_{4}\right.$, sea-salt, water) at small number median radii. Their total extinction, which is either strongly or totally dominated by scattering, shows a maximum at about $0.1-0.2 \mu \mathrm{m}$ for accumulation mode particles and less than $0.1 \mu \mathrm{m}$ for coarse mode particles, before decreasing again to very small values for large number median radii. The maximum scattering is calculated to be around the expected value (Sect. 2 and Eq. 1) of $100 \mathrm{~nm}$ aerosol radius at $550 \mathrm{~nm}$ 15 wavelength.

The $g$ for all particle single components is presented in Fig. $2 \mathrm{~d}$ for $550 \mathrm{~nm}$ incident light. For small radii, accumulation mode aerosols scatter nearly as much light in the forward as in the backward direction; the values of $g$ are low $(<0.1)$ and increase rapidly with aerosol size, since large particles favor scattering in the forward direction. Further 20 increase of the aerosol radius affects $g$ to a lesser extent, as it stays within a range from 0.7 to 0.9 . The same picture appears for coarse mode particles, with the only difference being the fact that the changes of $g$ are less sensitive to the modal radius changes. This is attributed to the wider distribution assumed $(\sigma=2.0$, compared to $\sigma=1.59$ for accumulation mode aerosols); for the very small particle populations, $g$ is also higher with a value of about 0.4 , again due to the wider distribution that is assumed. For both accumulation and coarse modes the increase of $g$ with size comes from the property of large particles to favor scattering in the forward direction.

Figure $2 e$ shows the results of the SSA for all aerosol components at $550 \mathrm{~nm}$. The 16039

\section{Global error maps of aerosol optical properties}

K. Tsigaridis et al.

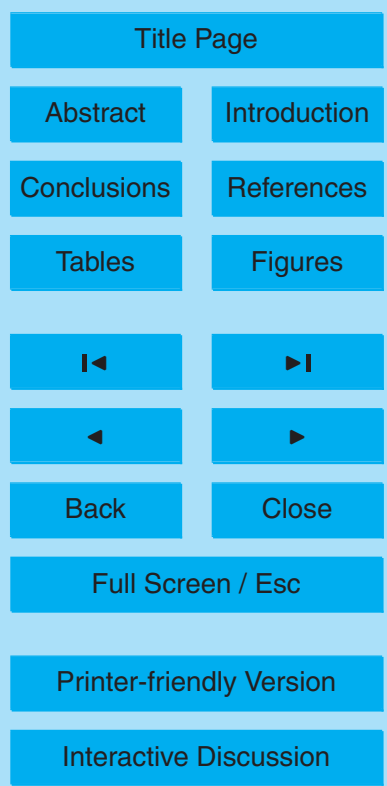


non-absorbing aerosols at the given wavelength, namely $\mathrm{SO}_{4}, \mathrm{H}_{2} \mathrm{O}$ and sea-salt, have a SSA value of one for all radii. The strong absorber BC has the lowest SSA, which increases from very low values (pure absorption) for the very small particle populations to more than 0.5 for large particles (roughly equal importance of absorption and scat5 tering). OC and dust have a maximum in the SSA (stronger domination of scattering on the total extinction) for sizes between 0.03 to $0.2 \mu \mathrm{m}$. OC has sharper slopes for the small and large particles compared to dust, due to the narrower lognormal distribution assumed, an effect also calculated for the case of $g$. For almost all cases studied (except the particles close to $0.01 \mu \mathrm{m}$ for $\mathrm{OC}$ ) scattering dominates absorption and values 10 of SSA are greater than 0.5 .

\subsection{Optical properties of aerosol mixtures}

In order to study the effect of mixing on aerosol optical properties, we selected a BCrich accumulation mode aerosol mixture with $20 \%$ BC, $40 \%$ OC and $40 \% \mathrm{SO}_{4}$ per volume, a composition typical of biomass burning aerosols with anthropogenic influence. Assuming lower $\mathrm{SO}_{4}$ and higher $\mathrm{OC}$ contribution as a proxy of a less polluted air mass, does not affect the results significantly. Varying the contribution of $\mathrm{OC}$ and $\mathrm{SO}_{4}$ does not change the results significantly, due to the similar refractive indices of the two components. This case study was conducted for a dry aerosol population. The optical properties calculated by the model are presented in Fig. 3; the externally mixed aerosols scatter more effectively than the two other mixed cases and are the weakest absorbers when compared with the homogeneously mixed and concentric sphere aerosols throughout the studied size spectrum. The homogeneous mixture is calculated to have an even higher absorption than in the case of concentric sphere aerosols, but this is expected to be an overestimation (within 15\%; Lesins et al., 2002) due to the widely used volume-weighted mixing of the refractive indices adopted (Bond et al., 2006). Concerning scattering, the homogeneous mixture is calculated to have higher specific scattering coefficients for aerosol populations with number median radii below $0.2 \mu \mathrm{m}$ and lower for larger particles. Overall, the total light extinction by the

Global error maps of aerosol optical properties

K. Tsigaridis et al.

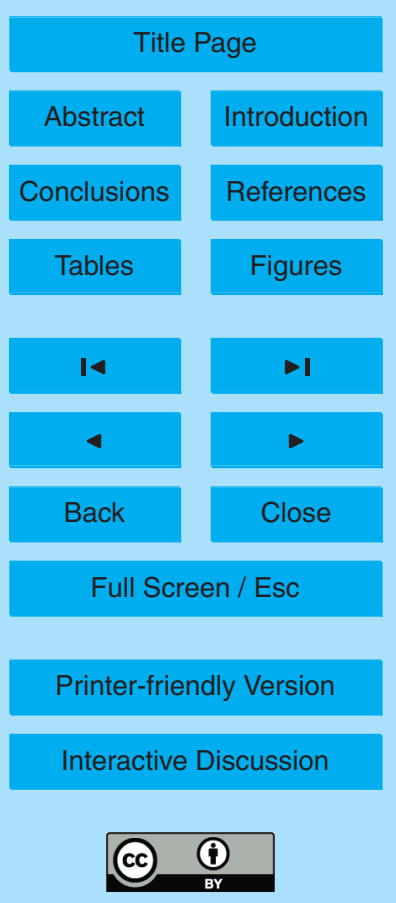


BC-rich mixed aerosol appears to be the highest for the homogeneous mixture.

The presence of an absorbing medium at the core of the particle (in our case, BC) makes the particle capable to absorb more light when compared to a pure particle with the same amount of absorbing components, as in the case of the external mixture 5 absorption. The reason is that the transparent outer shell of the particle acts as a lens (Fuller et al., 1999), focusing the light to the core of the particle, where the absorbing medium lies. Having more incident light reaching the absorbing core, more light is absorbed compared to the case of a pure BC particle; this effect is called absorption amplification. In general, the smaller the particle core for a given particle size, the greater the absorption amplification (Fig. 4), which means that small amounts of BC present in the core of a particle affect more the aerosol absorption when compared to particles with larger amounts of BC. Further, for a given BC core size, the larger the particle the higher the absorption amplification. This implies that during aerosol ageing, particles that increase their size due to condensation will be more efficient absorbers, even if the condensing material is purely scattering. In addition, as the refractive index of the shell increases, the lens effect is enhanced, which makes sulfate shells more efficient than water shells, for the same aerosol core and total size (Fuller, 1995). If the core is not exactly at the center of the particles, the lens effect diminishes and can lead up to $15 \%$ reduction in absorption compared to the concentric sphere particles (Fuller 20 et al., 1999).

For the case of $g$, the very small particle populations are calculated to have $g$ values close to zero, which increase when aerosol modal radius increases. When the number median radius exceeds approximately $0.2 \mu \mathrm{m}$, the $g$ of the homogeneous mixtures lowers its increase rate, approaching its maximum value for aerosol modal radiuses at about $1 \mu \mathrm{m}$. The externally mixed aerosols and the concentric sphere ones are calculated to have the same increase in $g$ : strong increase similar to that of the homogeneous mixture up to about $0.2 \mu \mathrm{m}$, stabilization between $0.2-0.5 \mu \mathrm{m}$ modal radius, and a slighter increase afterwards. The externally mixed particles approach a maximum of about 0.85 , although the concentric spheres with a modal radius larger than
Global error maps of aerosol optical properties

K. Tsigaridis et al.

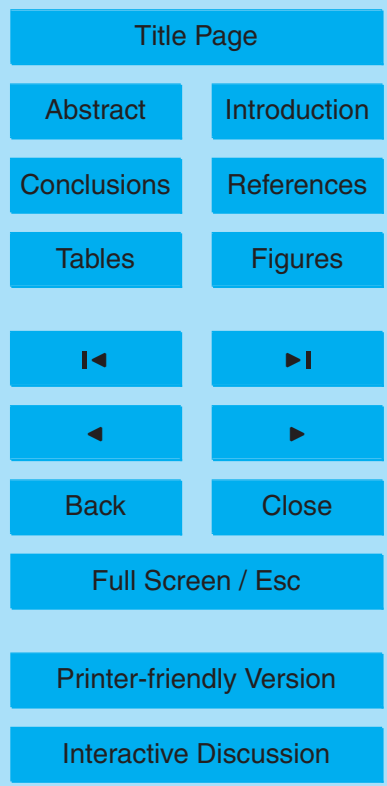


about $5 \mu \mathrm{m}$ are calculated to have a sharp drop in their $g$. The explanation of this might lie in the different assumptions for large particles between the two Mie codes used. The homogeneous aerosol case is calculated to have on average $15 \%$ higher $g$ than the coated spheres, consistent with the $10 \%$ difference calculated by Lesins et al. (2002).

5 The SSA of the BC-rich mixture under consideration is calculated to increase from values close to zero for very small particle populations (strongly absorbing) close to their maximum value at particles of about $0.1 \mu \mathrm{m}$ number median radius, and then remain roughly constant when further increasing the aerosol size. The external mixture has the highest SSA since it has the highest scattering and lowest absorption. This 10 might be a result of the external mixture assumption, for which all externally mixed accumulation mode aerosols have the same radius, which makes the total BC mass to be present in less particles with highest radius consisting of pure $\mathrm{BC}$, in contrast with the mixed aerosol that more and smaller particles will be able to absorb. The homogeneous mixture is calculated to have the lowest SSA throughout most of the 15 size spectrum. This result is expected to be an upper limit, since the mixing rule for the refractive indices used here overestimates absorption (Bond et al., 2006).

\subsection{AOD, $g$ and SSA uncertainty}

In the following section, the results of the AOD, $g$ and SSA are presented, together with their corresponding uncertainties, as derived by the range of cases studied here 20 and described in Sect. 2.3. For all three aerosol parameters, the spatial and temporal (monthly and mean annual) distribution of the reference case, the mean, the median, and the $1 \sigma$ and $2 \sigma$ uncertainty ranges discussed below are available online as supplementary material to this work (NetCDF files, http://www-Iscedods.cea.fr/aerocom/ AOD_UNCERTAINTY_MAPS/). The uncertainty range is calculated here as a percent25 age and is defined as the 1- or 2-sigma absolute range of the optical property under consideration over the median value of the same range. Note that the median value is not at the center of the range for most cases. As a general rule, the median value is below the center of the range when coarse aerosols dominate, and above when the

Global error maps of aerosol optical properties

$\mathrm{K}$. Tsigaridis et al.

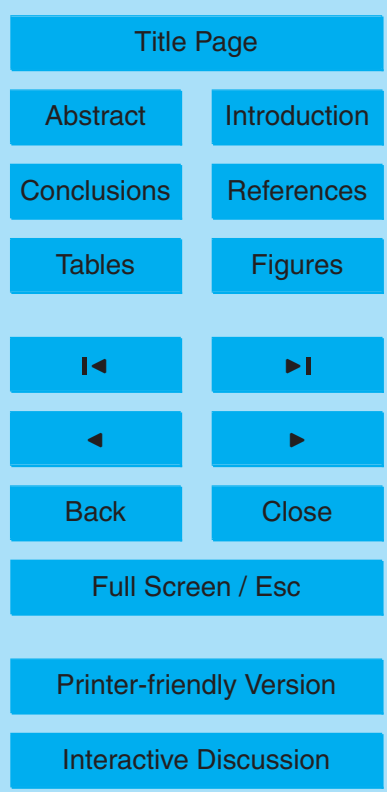


aerosol population consists of accumulation mode particles.

The reference (unperturbed) and median AOD calculated by the combination of cases described in Sect. 2.3 for January and July 2000 are presented on Fig. 5. High AOD values are calculated above dust source regions and downwind, regardless the

5 fact that large particles have low extinction efficiency, due to the very high aerosol load. Additionally, AOD is calculated to be elevated in regions with high accumulation mode aerosol emissions, namely anthropogenic pollution and biomass burning sources, due to a combination of high aerosol load and small particle size which have high light extinction capabilities. AOD appears to have a strong seasonality reflecting the sea10 sonality of aerosol sources, particularly due to the seasonal shift in biomass burning regions from winter to summer.

The annual mean of the globally averaged median AOD of all cases described in Sect. 2.3 is calculated to be 0.084 . The mean and reference AOD are calculated to be similar to the median AOD for all cases considered and both equal to 0.083 . This value 15 is lower when compared to the AEROCOM B experiment calculations for our reference case (Kinne et al., 2006), with the difference attributed to the aerosol associated water calculation: for the AEROCOM B experiment a growth factor based on aerosol hygroscopicity has been used for the optical calculations, while in the present work the amount of aerosol water used in the Mie code comes directly from the online model calculations. This approach might have included an underestimation on the humidity growth of aerosols, which in any case is not expected to affect much the relative error. Nevertheless, our annual mean global value, including our other cases calculated for the PDF, are within the AEROCOM published range (Kinne et al., 2006).

The AOD uncertainty range varies considerably spatially, as can be seen in Fig. 6; 25 the greatest uncertainty range is calculated in regions where the contribution from the coarse aerosols (both dust and sea-salt) and from anthropogenic pollution is large. The $1 \sigma$ and $2 \sigma$ uncertainty ranges are quite different, reflecting the fact that the range of aerosol properties studied gives a wide-spread distribution of AOD. This underlines the importance of the accurate knowledge of the aerosol properties studied here (mixing

\section{Global error maps of aerosol optical properties}

K. Tsigaridis et al.

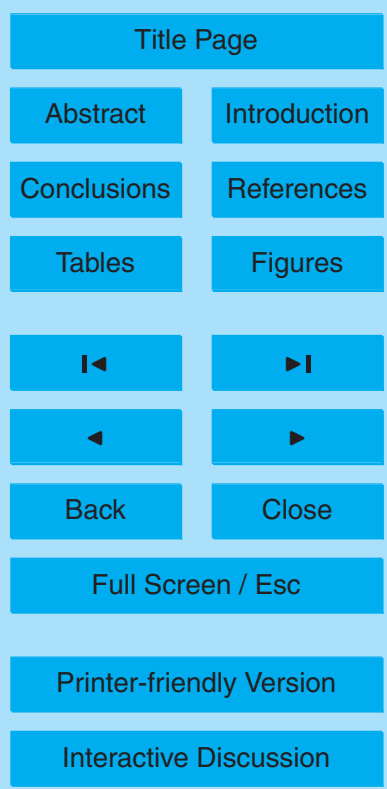


state, aerosol size and aerosol associated water) needed to calculate the direct aerosol effect on climate. The annual mean $2 \sigma$ uncertainty range reaches a maximum of about $58 \%$ above the Saharan desert, which remains fairly constant throughout the year, while the seasonal maxima follow the distribution of sea-salt $(59 \%$ in January above 5 the Southern Ocean, $70 \%$ in July above the North Atlantic).

The mean and median $g$ calculated by the combination of cases described in Sect. 2.3 for January and July 2000 are presented in Fig. 7, while for SSA in Fig. 8. The $g$ is more strongly dependent on aerosol size than on aerosol composition and state of mixing (Figs. 2 and 3). In general, aerosols in regions with large accumulation mode 10 aerosol sources (e.g. biomass burning in Africa and South America) scatter less light in the forward direction (lower g-values). It is noteworthy that the $g$ of the accumulation mode aerosols dominates, since the contribution of coarse aerosols to the total AOD is very small over most regions. Concerning SSA, it approaches unity to most areas of the globe (mainly scattering aerosols), except the regions where BC and/or dust are present. When this is the case, absorption becomes significant and SSA decreases.

The uncertainty introduced by the perturbations of the reference case (Sect. 2.3) to $g$ and SSA calculations is not as large as that of the AOD calculations: the annual mean $2 \sigma$ uncertainty for $g$ reaches a maximum of about $16 \%$ based on the PDF constructed by all the simulations (Fig. 9). The maximum uncertainty is higher in June (18\%) compared to January (14\%) due to stronger biomass burning emissions in the tropics at that time. For SSA, the annual mean $2 \sigma$ uncertainty can go up to $22 \%$ (18\% in January, $28 \%$ in July; Fig. 10). It is interesting to note that for SSA the $1 \sigma$ and $2 \sigma$ uncertainties do not differ much, which means that the variation of SSA is small, compared to the variations of AOD and $g$. This leads to a narrow distribution of the SSA values present

in the PDF, contrasting the cases of AOD and $g$ where the range of values is more widespread. The SSA is strongly affected by the state of mixing changes, rather than the other microphysical aerosol properties (size and water content). The $g$ uncertainty maximizes above regions where aerosols are small, since for larger radii $g$ does not change much (Figs. 2 and 3); on the other hand, SSA uncertainty is maximum above
Global error maps of aerosol optical properties

K. Tsigaridis et al.

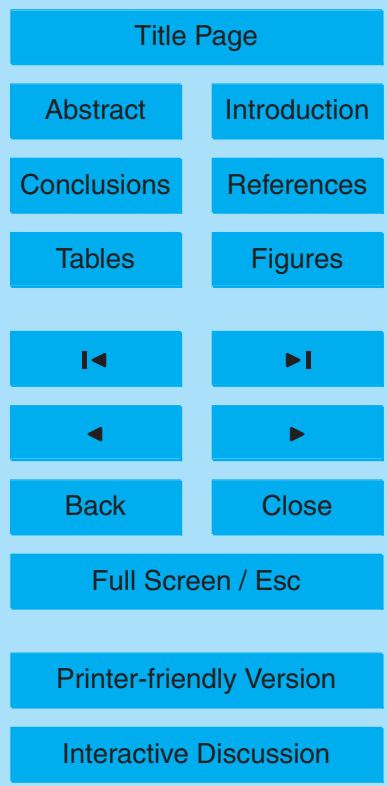


i) regions where the absorbing aerosol contribution (BC and dust) is high and

ii) downwind of $B C$ abundant regions, showing that even very small $B C$ amounts can affect the SSA considerably.

\section{Conclusions and perspectives}

5 The aerosol absorption coefficient, scattering coefficient, extinction coefficient, $g$ and SSA for all possible aerosol mixtures containing $\mathrm{BC}, \mathrm{OC}, \mathrm{SO}_{4}$, sea-salt, dust and $\mathrm{H}_{2} \mathrm{O}$ were calculated for lognormally distributed accumulation and coarse mode particles for the size range from $10 \mathrm{~nm}$ to $10 \mu \mathrm{m}$ number median radius, for three aerosol mixing states, external mixture, homogeneous internal mixture and coated sphere particles.

10 Small absorbing aerosols are the most important contributors to the light absorption, while the extinction maximizes at aerosols with similar circumference to the incident light wavelength. BC is the most important absorber, followed by dust and OC which are weak absorbers. All the optical properties were affected by the mixing state, especially the aerosol absorption when absorbing constituents are present.

15 By using the output of the general circulation model LMDz-INCA which participated in the AEROCOM B experiment as a reference, the AOD, $g$ and SSA of aerosols were calculated for a number of cases, with varying aerosol microphysical properties: namely, mixing state (three different cases), aerosol size ( $\pm 20 \%$ with $2 \%$ intervals) and aerosol associated water $( \pm 50 \%$ with $5 \%$ intervals). The spatially and temporally results obtained were used for the construction of a PDF, also variable in space and time, in order to estimate the uncertainty associated with the three aerosol microphysical properties under consideration. The AOD uncertainty range calculated maximizes to $70 \%$, while for $g$ and SSA the uncertainty reaches $18 \%$ and $28 \%$ respectively. Both AOD and $g$ have a relatively broad distribution of values, while SSA is calculated to vary less in 25 the range of cases under consideration, with the most important parameter affecting SSA being the mixing state. The calculations were done for the wavelength of $550 \mathrm{~nm}$,

Global error maps of aerosol optical properties

K. Tsigaridis et al.

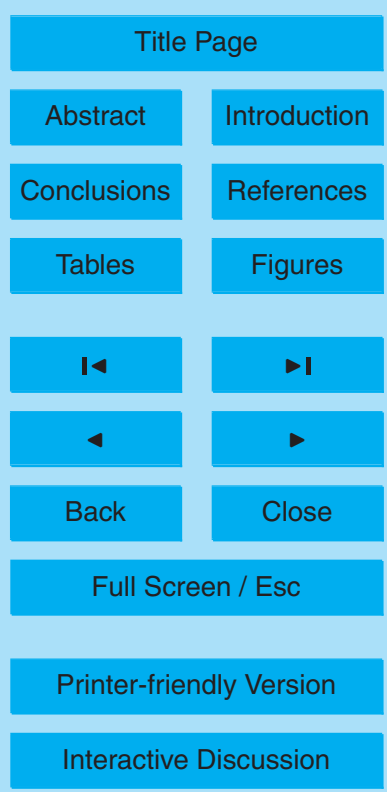

Interactive Discussion 
but the method developed could be applied to all wavelengths for which the refractive indices of the individual aerosol components are known.

The mapped uncertainty will be used in the future as an a priori model error for the use in the GEMS-ECMWF aerosol assimilation system. This uncertainty analysis 5 can also be used for the estimation of the error introduced to the radiative forcing calculated by models, due to the uncertainty on the aerosol optical properties and the representation of aerosol microphysics in global models. This work has already started and will be the topic of a forthcoming paper.

Acknowledgements. Support by the European Commission via the FP6 project GEMS 10 (SIP4-CT-2004-516099) is gratefully acknowledged.

INST/ The publication of this article is financed by CNRS-INSU.

\section{References}

Bohren, C. F. and Huffman, D. R.: Absorption and scattering of light by small particles, John Wiley and Sons, New York, USA, 1983.

Bond, T. C., Habib, G., and Bergstrom, R. W.: Limitations in the enhancement of visible light absorption due to mixing state, J. Geophys. Res., 111, D20211, doi:10.1029/2006JD007315, 2006.

Bond, T. C. and Bergstrom, R. W.: Light absorption by carbonaceous particles: an investigative review, Aerosol Sci. Tech., 40, 27-67, 2006.

d'Almeida, G. A., Koepke, P., and Shettle, E. P.: Atmospheric aerosols: global climatology and radiative characteristics, A. Deepak, Hampton, VA, USA, 1991.

Fuller, K. A.: Scattering and absorption cross sections of compounded spheres - 3: Spheres 1995.

\section{ACPD}

8, 16027-16059, 2008

Global error maps of aerosol optical properties

K. Tsigaridis et al.

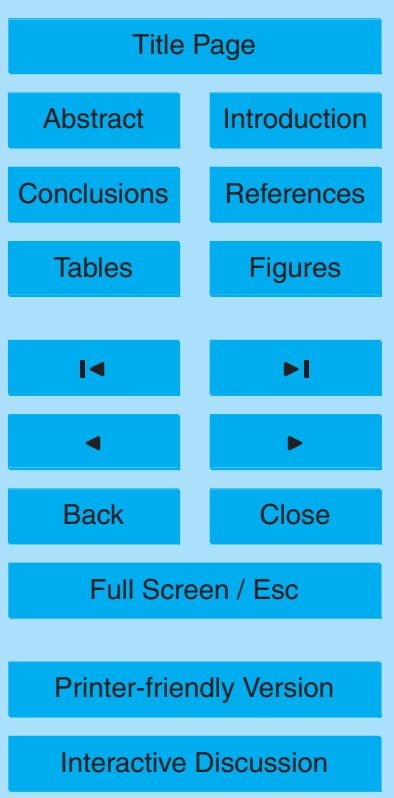


Fuller, K. A., Malm, W. C., and Kreidenweis, S. M.: Effects of mixing on extinction by carbonaceous particles, J. Geophys. Res., 104, 15941-15954, 1999.

Hale, G. M. and Querry, M. R.: Optical constants of water in the $200 \mathrm{~nm}$ to $200 \mathrm{~mm}$ wavelength region, Appl. Optics, 12, 555-563, 1973.

5 Hauglustaine, D. A., Hourdin, F., Jourdain, L., Filiberti, M.-A., Walters, S., Lamarque, J.-F., and Holland, E. A.: Interactive chemistry in the Laboratoire de Météorologie Dynamique general circulation model: description and background tropospheric chemistry evaluation, J. Geophys. Res., 109, D04314, doi:10.1029/2003JD003957, 2004.

Hourdin, F. and Armengaud, A.: The use of finite-volume methods for atmospheric advection of trace species - Part 1: test of various formulations in a general circulation model, Mon. Weather. Rev., 127, 822-837, 1999.

Jacobson, M. Z., Kaufman, Y. J., and Rudich, Y.: Examining feedbacks of aerosols to urban climate with a model that treats 3-D clouds with aerosol inclusions, J. Geophys. Res., 112, doi:10.1029/2007JD008922, 2007.

Kinne, S., Schulz, M., Textor, C., Guibert, S., Balkanski, Y., Bauer, S. E., Berntsen, T., Berglen, T. F., Boucher, O., Chin, M., Collins, W., Dentener, F., Diehl, T., Easter, R., Feichter, J., Fillmore, D., Ghan, S., Ginoux, P., Gong, S., Grini, A., Hendricks, J., Herzog, M., Horowitz, L., Isaksen, I., Iversen, T., Kirkevåg, A., Kloster, S., Koch, D., Kristjansson, J. E., Krol, M., Lauer, A., Lamarque, J. F., Lesins, G., Liu, X., Lohmann, U., Montanaro, V., Myhre, G., Penner, J., Pitari, G., Reddy, S., Seland, O., Stier, P., Takemura, T., and Tie, X.: An AeroCom initial assessment - optical properties in aerosol component modules of global models, Atmos. Chem. Phys., 6, 1815-1834, 2006,

http://www.atmos-chem-phys.net/6/1815/2006/.

Lesins, G., Chylek, P., and Lohmann, U.: A study of internal and external mixing scenarios and its effect on aerosol optical properties and direct radiative forcing, J. Geophys. Res., 107, 4094, doi:10.1029/2001JD000973, 2002.

Liu, X., Penner, J. E., Das, B., Bergmann, D., Rodriguez, J. M., Strahan, S., Wang, M., and Feng, Y.: Uncertainties in global aerosol simulations: Assessment using three meteorological data sets, J. Geophys. Res., 112, D11212, doi:10.1029/2006JD008216, 2007.

30 McMurry, P. H.: A review of atmospheric aerosol measurements, Atmos. Environ., 34, 19591999, 2000.

Moteki, N., Kondo, Y., Miyazaki, Y., Takegawa, N., Komazaki, Y., Kurata, G., Shirai, T., Blake, D. R., Miyakawa, T., and Koike, M.: Evolution of mixing state of black carbon particles: Aircraft 
measurements over the western Pacific in March 2004, Geophys. Res. Lett., 34, L11803, doi:10.1029/2006GL028943, 2007.

Reddy, M. S., Boucher, O., Balkanski, Y., and Schulz, M.: Aerosol optical depths and direct radiative perturbations by species and source type, Geophys. Res. Lett., 32, L12803, doi:10.1029/2004GL021743, 2005.

Reid, J. S., Eck, T. F., Christopher, S. A., Koppmann, R., Dubovik, O., Eleuterio, D. P., Holben, B. N., Reid, E. A., and Zhang, J.: A review of biomass burning emissions - Part 3: Intensive optical properties of biomass burning particles, Atmos. Chem. Phys., 5, 827-849, 2005a, http://www.atmos-chem-phys.net/5/827/2005/.

10 Reid, J. S., Koppmann, R., Eck, T. F., and Eleuterio, D. P.: A review of biomass burning emissions - Part 2: intensive physical properties of biomass burning particles, Atmos. Chem. Phys., 5, 799-825, 2005b, http://www.atmos-chem-phys.net/5/799/2005/.

Shettle, E. P. and Fenn, R. W.: Models of the aerosols of the lower atmosphere and the effects of humidity variations on their optical properties, Project 7670, Air Force Geoph. Lab.,

15 Massachusetts, USA, 1979.

Song, C. H. and Carmichael, G. R.: The aging process of naturally emitted aerosol (sea-salt and mineral aerosol) during long range transport, Atmos. Environ., 33, 2203-2218, 1999.

Song, C. H., Maxwell-Meier, K., Weber, R. J., Kapustin, V., and Clarke, A.: Dust composition and mixing state inferred from airborne composition measurements during ACE-Asia C130 $20 \quad$ Flight \#6, Atmos. Environ, 39, 359-369, 2005.

Stier, P., Feichter, J., Kinne, S., Kloster, S., Vignati, E., Wilson, J., Ganzeveld, L., Tegen, I., Werner, M., Balkanski, Y., Schulz, M., Boucher, O., Minikin, A., and Petzold, A.: The aerosolclimate model ECHAM5-HAM, Atmos. Chem. Phys., 5, 1125-1156, 2005, http://www.atmos-chem-phys.net/5/1125/2005/.

Textor, C., Schulz, M., Kinne, S., et al.: Analysis and quantification of the diversities of aerosol life cycles within AeroCom, Atmos. Chem. Phys., 6, 1777-1813, 2006, http://www.atmos-chem-phys.net/6/1777/2006/.

Toon, O. B., Pollack, J. B., and Khare, B. N.: The optical constants of several atmospheric aerosol species: ammonium sulfate, aluminium oxide, and sodium chloride, J. Geophys. $30 \quad$ Res., 81, 5733-5748, 1976.

Toon, O. B. and Ackerman, T. P.: Algorithms for the calculation of scattering by stratified spheres, Appl. Optics, 20, 3657-3660, 1981.

Global error maps of aerosol optical properties

K. Tsigaridis et al.

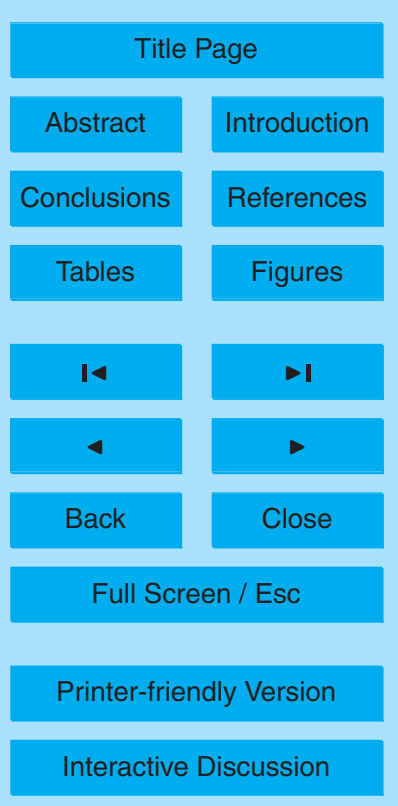




\section{ACPD}

8, 16027-16059, 2008

Global error maps of aerosol optical properties

Table 1. Single component refractive indices (at $550 \mathrm{~nm}$ ) and component densities $\left(\mathrm{kg} \mathrm{m}^{-3}\right)$ adopted for the present study.

\begin{tabular}{llll}
\hline Component & Refractive Index & Density $\left(\mathrm{kg} \mathrm{m}^{-3}\right)$ & Reference \\
\hline $\mathrm{BC}$ & $1.95-0.79 i$ & 1.8 & Bond and Bergstrom (2006) \\
$\mathrm{OC}$ & $1.53-0.006 i$ & 1.5 & S. Kinne (personal communication) \\
$\mathrm{SO}_{4}$ & $1.43-10^{-8} i$ & 1.769 & Toon et al. (1976) \\
$\mathrm{H}_{2} \mathrm{O}$ & $1.333-1.96 \cdot 10^{-9} i$ & 1.0 & Hale and Querry (1973) \\
Sea-salt & $1.5-10^{-8} i$ & 1.6 & Shettle et al. (1979) \\
Dust & $1.5-0.0332 i$ & 2.65 & Reddy et al. (2005) \\
\hline
\end{tabular}

Title Page

Abstract

Introduction

Conclusions

References

Tables

Figures

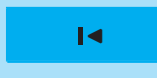

4

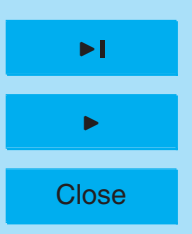

Back

Close

Full Screen / Esc

Printer-friendly Version

Interactive Discussion 

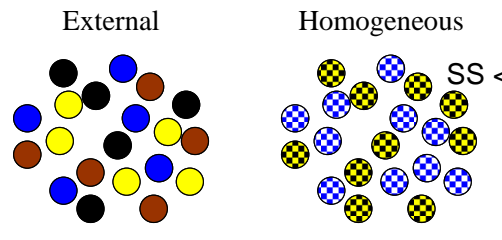

Concentric
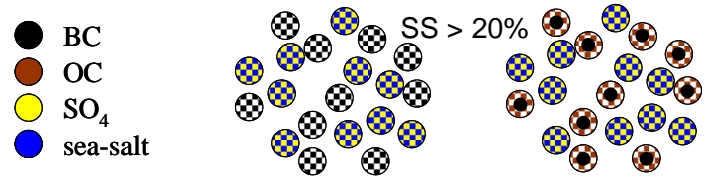

(2) $\mathrm{BC} / \mathrm{OC} / \mathrm{SO}_{4} / \mathrm{H}_{2} \mathrm{O}$ homogeneous mixture

(2) $\mathrm{OC} / \mathrm{SO}_{4} / \mathrm{H}_{2} \mathrm{O}$ homogeneous mixture with $\mathrm{BC}$ core

0 sea-salt $/ \mathrm{SO}_{4} / \mathrm{H}_{2} \mathrm{O}$ homogeneous mixture

(2) $\mathrm{BC} / \mathrm{OC} / \mathrm{H}_{2} \mathrm{O}$ homogeneous mixture

(2) $\mathrm{OC} / \mathrm{H}_{2} \mathrm{O}$ homogeneous mixture with $\mathrm{BC}$ core

(8) sea-salt $/ \mathrm{H}_{2} \mathrm{O}$ homogeneous mixture

(b)

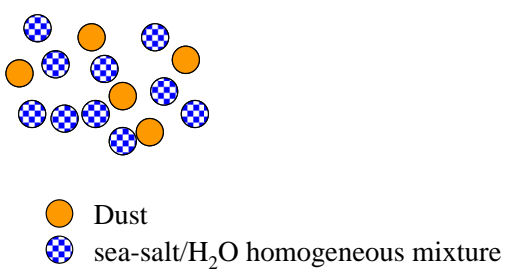

8, 16027-16059, 2008

Global error maps of aerosol optical properties

K. Tsigaridis et al.

Title Page

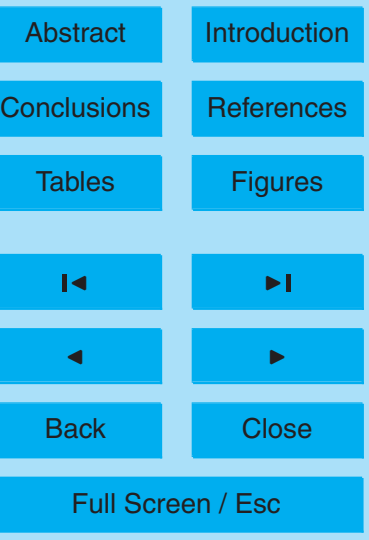

Printer-friendly Version

Interactive Discussion
Fig. 1. Schematic representation of aerosol mixing. (a) accumulation mode and (b) coarse mode. For the accumulation mode aerosols, $\mathrm{SO}_{4}$ will be present at the sea-salt mixtures if sea-salt is more than $20 \%$ of the dry aerosol volume, otherwise sea-salt will only mix with water (see text). 


\section{ACPD}

(a)

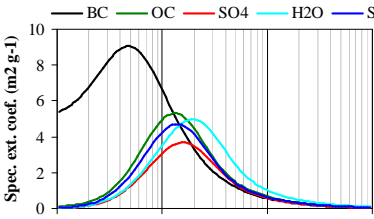

(b)

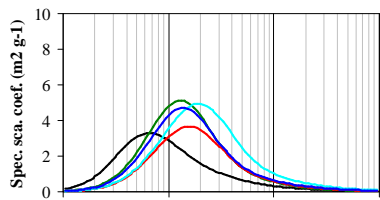

(c)

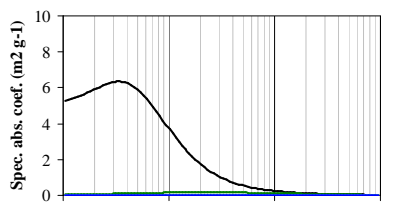

(d)
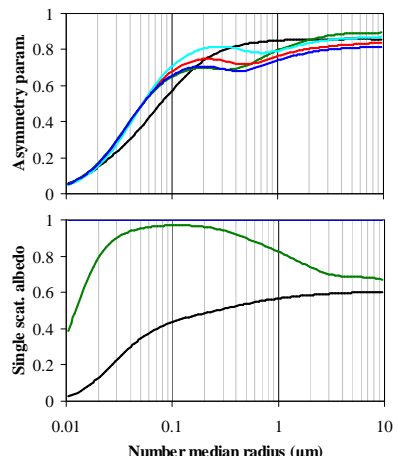
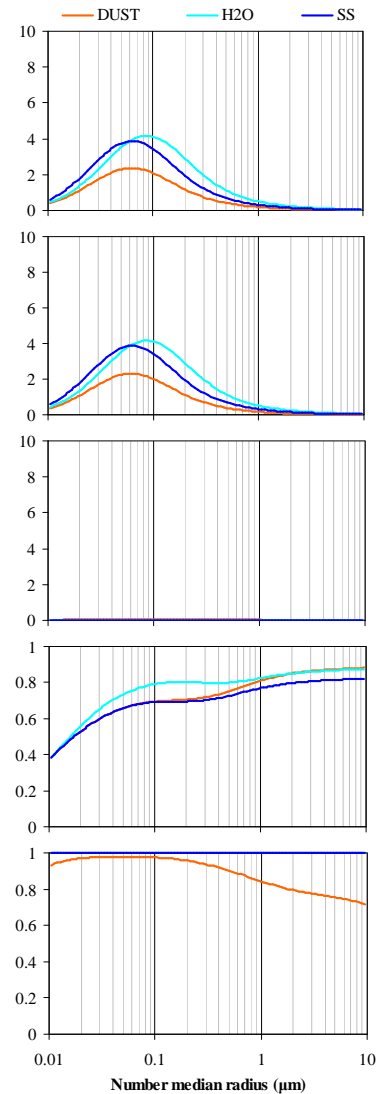

Fig. 2. Specific extinction coefficient (a), specific scattering coefficient (b), specific absorption coefficient (c), asymmetry parameter (d) and single scattering albedo (e) as a function of modal radius for the single components of aerosol mixtures, both for accumulation mode (left, $\sigma=1.59$ ) and coarse mode (right, $\sigma=2.0$ ) at $550 \mathrm{~nm}$.

8, 16027-16059, 2008

Global error maps of aerosol optical properties

K. Tsigaridis et al.

Title Page

Abstract

Introduction

Conclusions

References

Tables

Figures

14

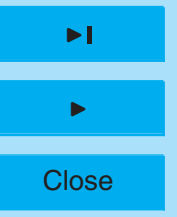

Back

Close

Full Screen / Esc

Printer-friendly Version

Interactive Discussion 


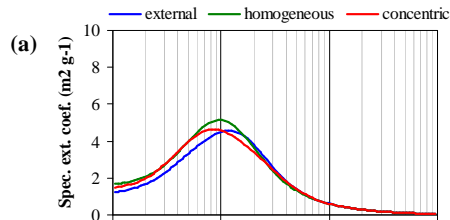

(b)

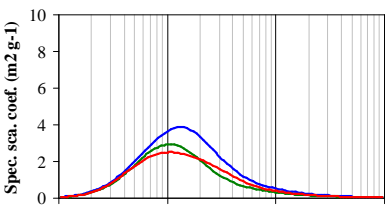

(c)

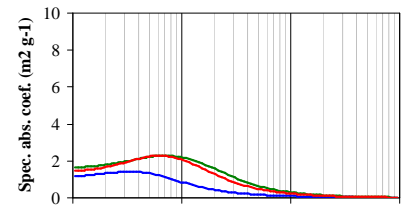

(d)

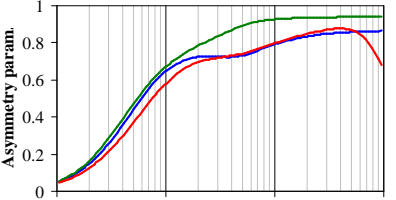

(e)

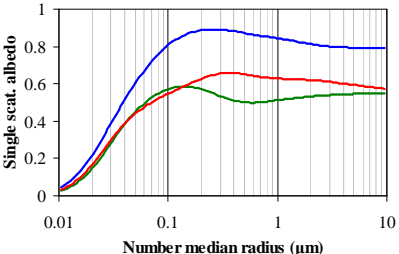

\section{ACPD}

8, 16027-16059, 2008

Global error maps of aerosol optical properties

K. Tsigaridis et al.

Title Page

Abstract

Introduction

Conclusions

References

Tables

Figures

14

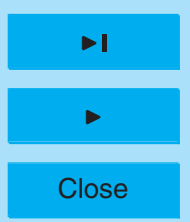

Back

Close

Full Screen / Esc

Printer-friendly Version

Interactive Discussion

Fig. 3. Specific extinction coefficient (a), specific scattering coefficient (b), specific absorption coefficient (c), asymmetry parameter (d) and single scattering albedo (e) as a function of modal radius for the dry hypothetical accumulation mode mixture of $20 \%$ BC, $40 \%$ OC, $40 \%$ SO4 at $550 \mathrm{~nm}$ 


\section{ACPD}

8, 16027-16059, 2008

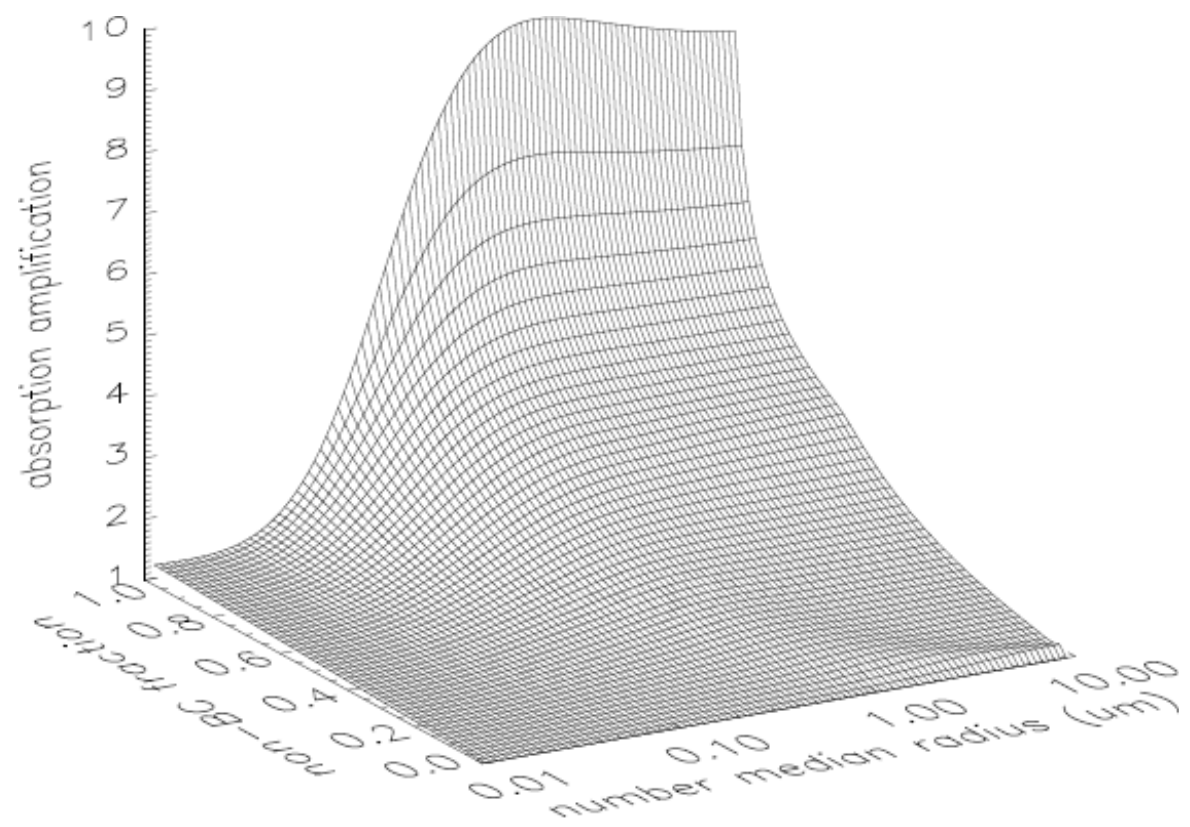

Global error maps of aerosol optical properties

K. Tsigaridis et al.

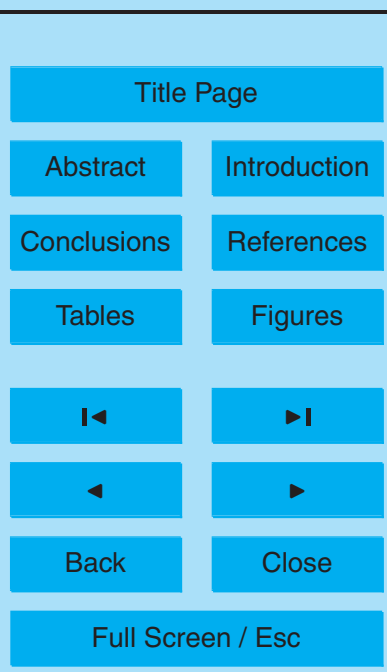

Fig. 4. Absorption amplification as a function of aerosol size and $B C$ content.

Printer-friendly Version

Interactive Discussion 

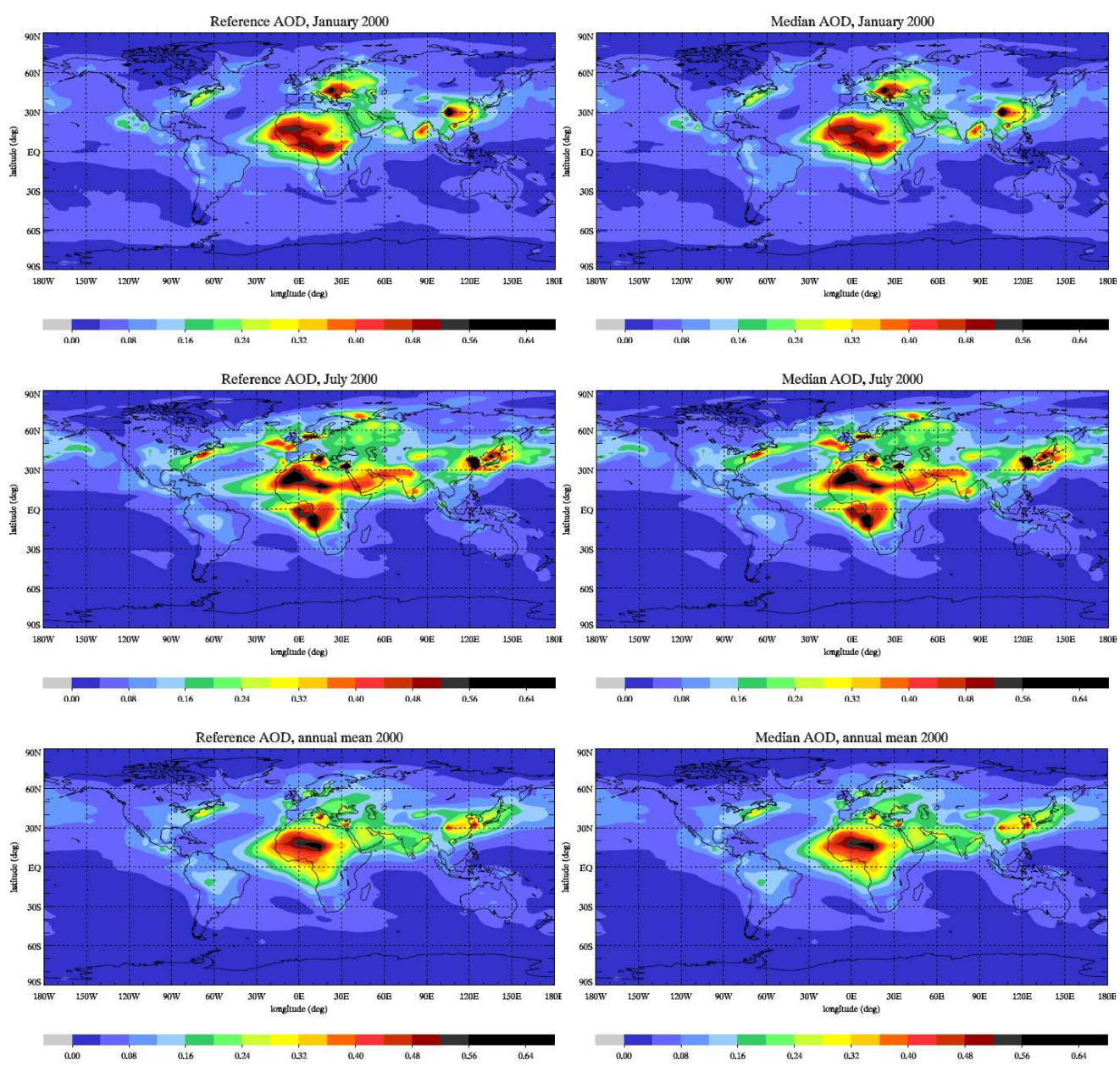

Fig. 5. Reference (left) and median (right) AOD of all simulations described in Sect. 2.3 for January (top), July (medium) and annual mean (bottom). 16054
ACPD

8, 16027-16059, 2008

Global error maps of aerosol optical properties

K. Tsigaridis et al.

\section{Title Page}

\section{Abstract}

Introduction

Conclusions

References

Tables

Figures

$1<$

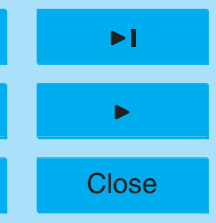

Back

Full Screen / Esc

Printer-friendly Version

Interactive Discussion

(c) 
1-sigma AOD range (\%), January 2000
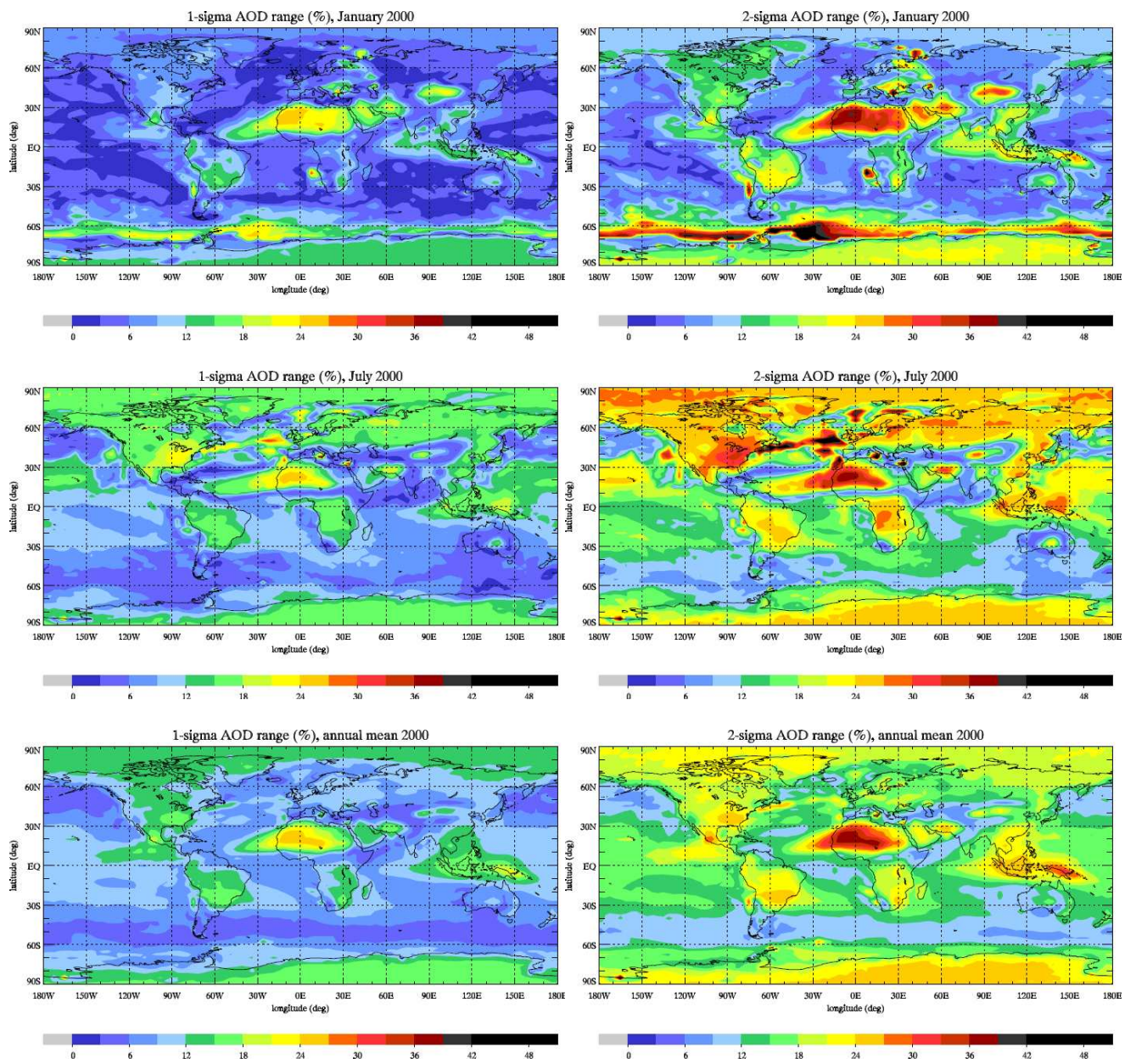

Fig. 6. Spatial variability of the $1 \sigma$ (left) and $2 \sigma$ (right) PDF AOD uncertainty range from all simulations described in Sect. 2.3 for January (top), July (medium) and annual mean (bottom).
ACPD

8, 16027-16059, 2008

Global error maps of aerosol optical properties

K. Tsigaridis et al.

\section{Title Page}

\begin{tabular}{|c|c|}
\hline Abstract & Introduction \\
\hline Conclusions & References \\
\hline Tables & Figures \\
\hline I & \\
\hline & \\
\hline & \\
\hline Back & Close \\
\hline Full Screen / Esc
\end{tabular}

Printer-friendly Version

Interactive Discussion 

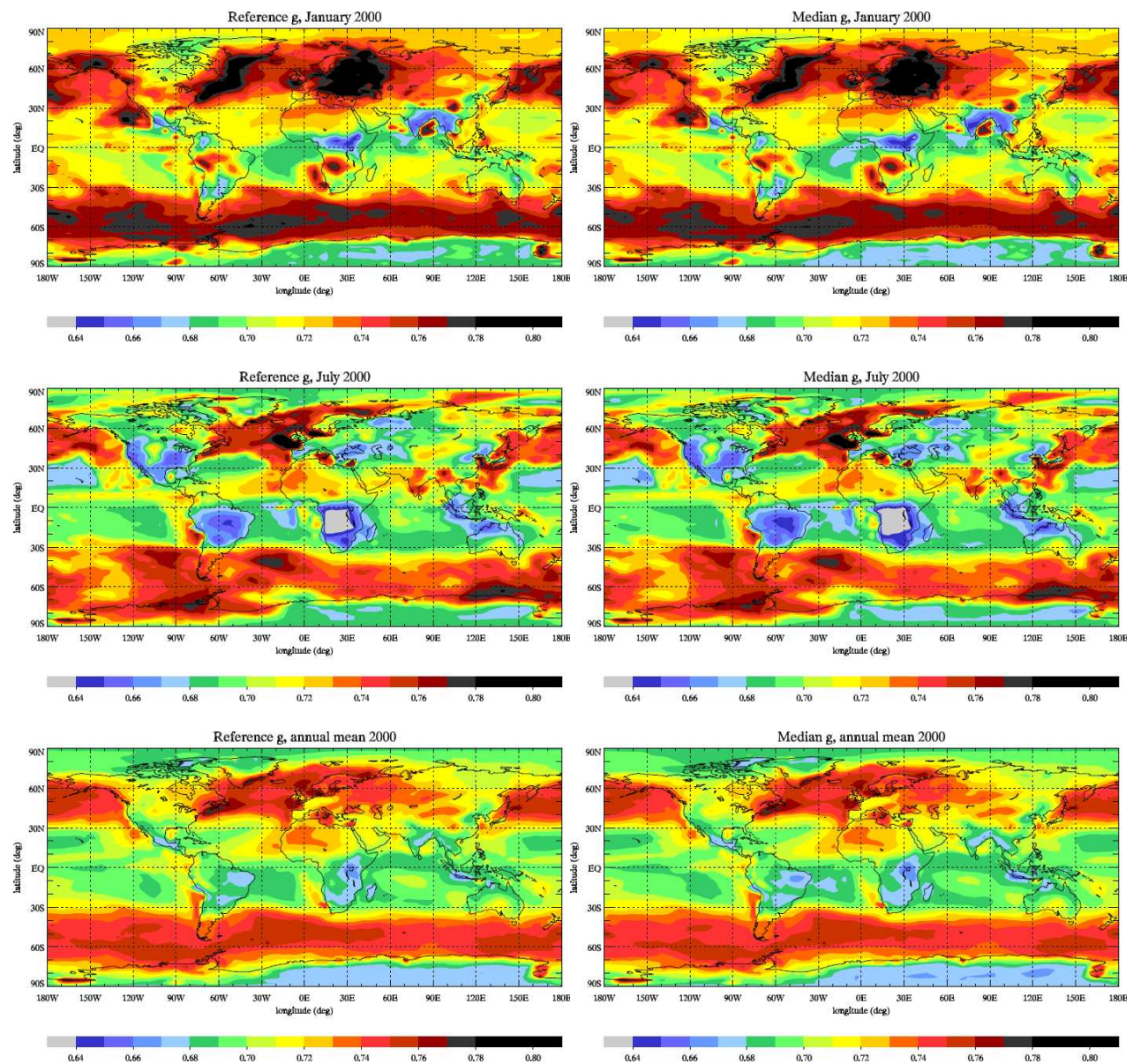

Fig. 7. Reference (left) and median (right) $g$ of all simulations described in Sect. 2.3 for January (top), July (medium) and annual mean (bottom).

\section{ACPD}

8, 16027-16059, 2008

Global error maps of aerosol optical properties

K. Tsigaridis et al.

\section{Title Page}

\begin{tabular}{|c|c|}
\hline Abstract & Introduction \\
\hline Conclusions & References \\
\hline Tables & Figures \\
\hline I & \\
\hline & \\
\hline Back & Close \\
\hline Full Screen / Esc
\end{tabular}

Printer-friendly Version

Interactive Discussion 
Reference SSA, January 2000
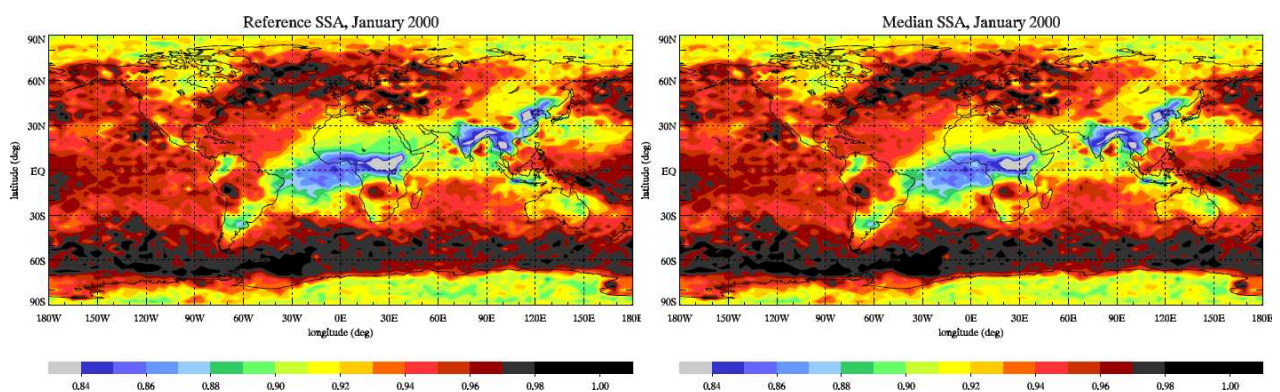

Reference SSA, July 2000
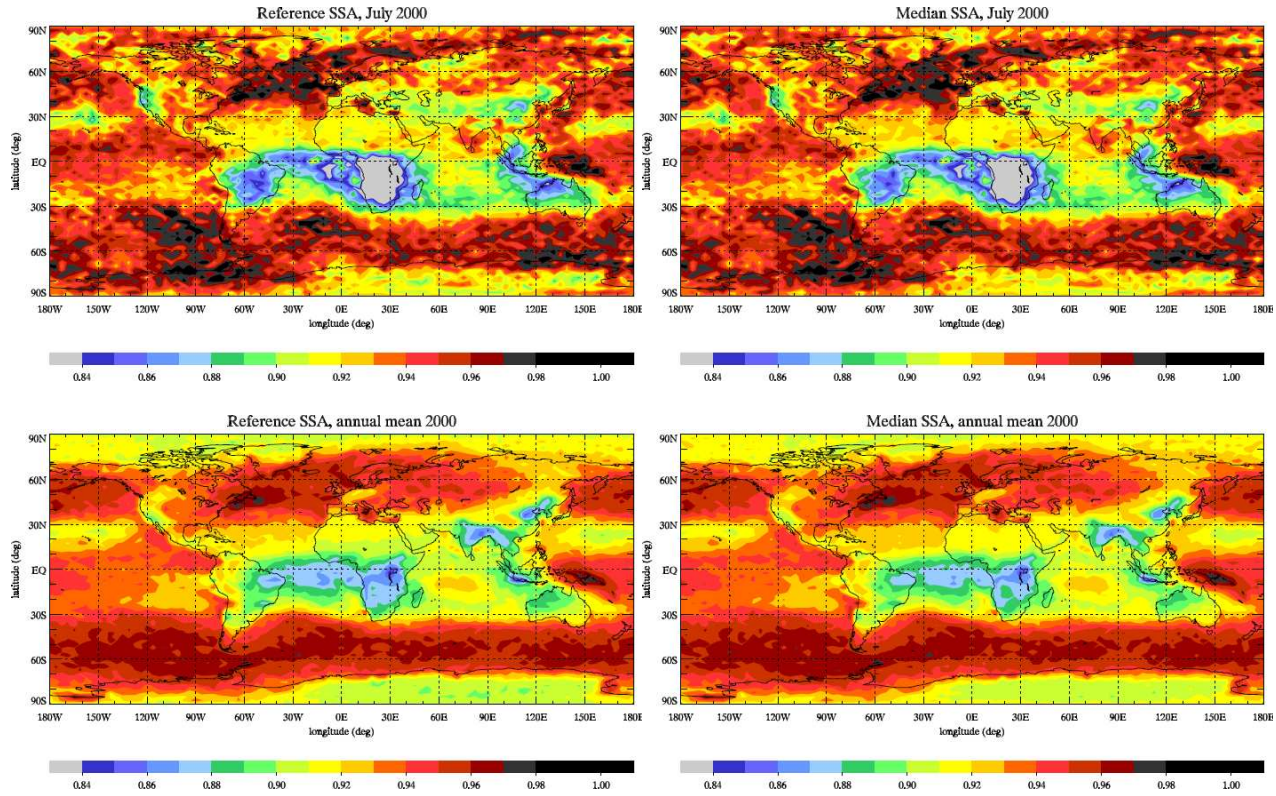

Median SSA, annual mean 2000

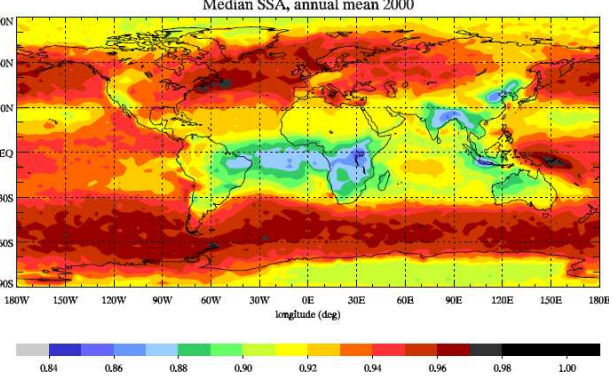

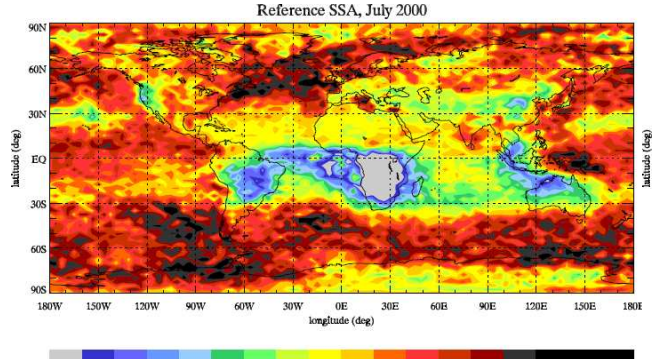

ACPD

8, 16027-16059, 2008

Global error maps of aerosol optical properties

K. Tsigaridis et al.

Fig. 8. Reference (left) and median (right) SSA of all simulations described in Sect. 2.3 for January (top), July (medium) and annual mean (bottom).
Title Page

\begin{tabular}{|c|c|}
\hline Abstract & Introduction \\
\hline Conclusions & References \\
\hline Tables & Figures \\
\hline I & \\
\hline & \\
\hline Back & Close \\
\hline
\end{tabular}

Full Screen / Esc

Printer-friendly Version

Interactive Discussion

(c) (i) 

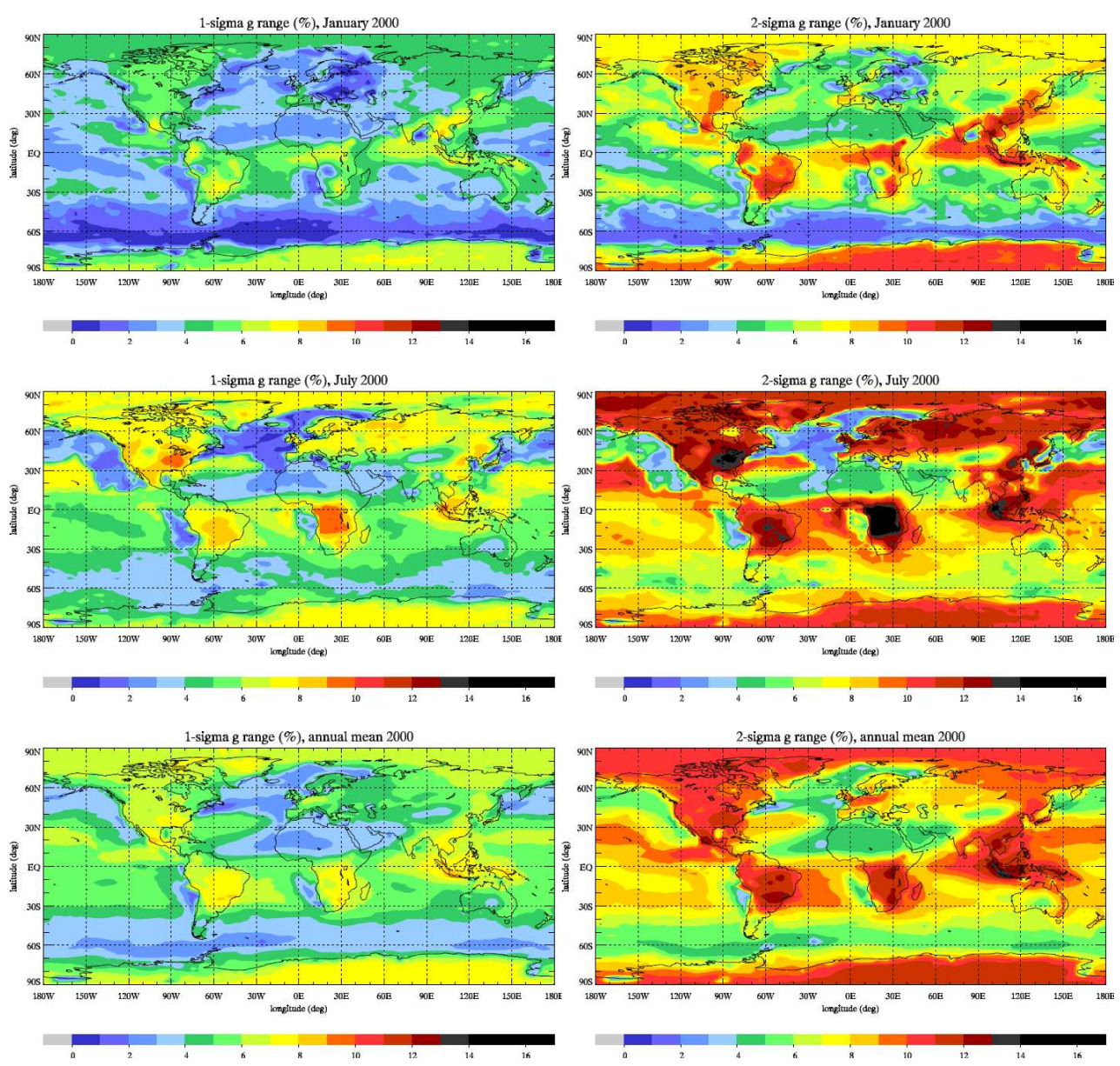

Fig. 9. Spatial variability of the $1 \sigma$ (left) and $2 \sigma$ (right) PDF $g$ uncertainty range from all simulations described in Sect. 2.3 for January (top), July (medium) and annual mean (bottom).

\section{8}

\section{ACPD}

$8,16027-16059,2008$

\section{Global error maps of aerosol optical properties}

K. Tsigaridis et al.

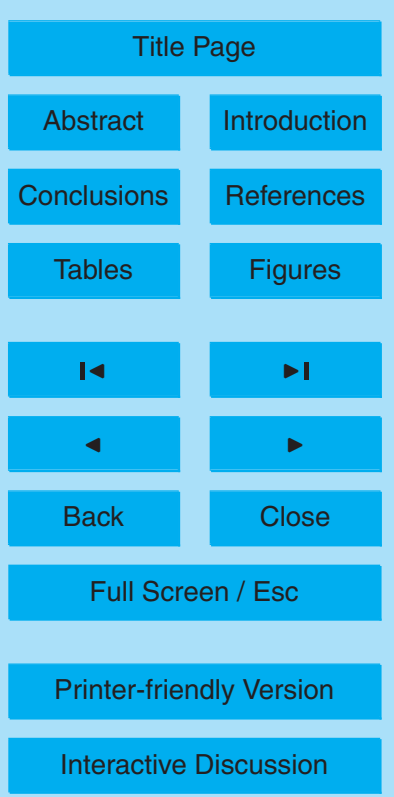

(ㄷ) (1) 

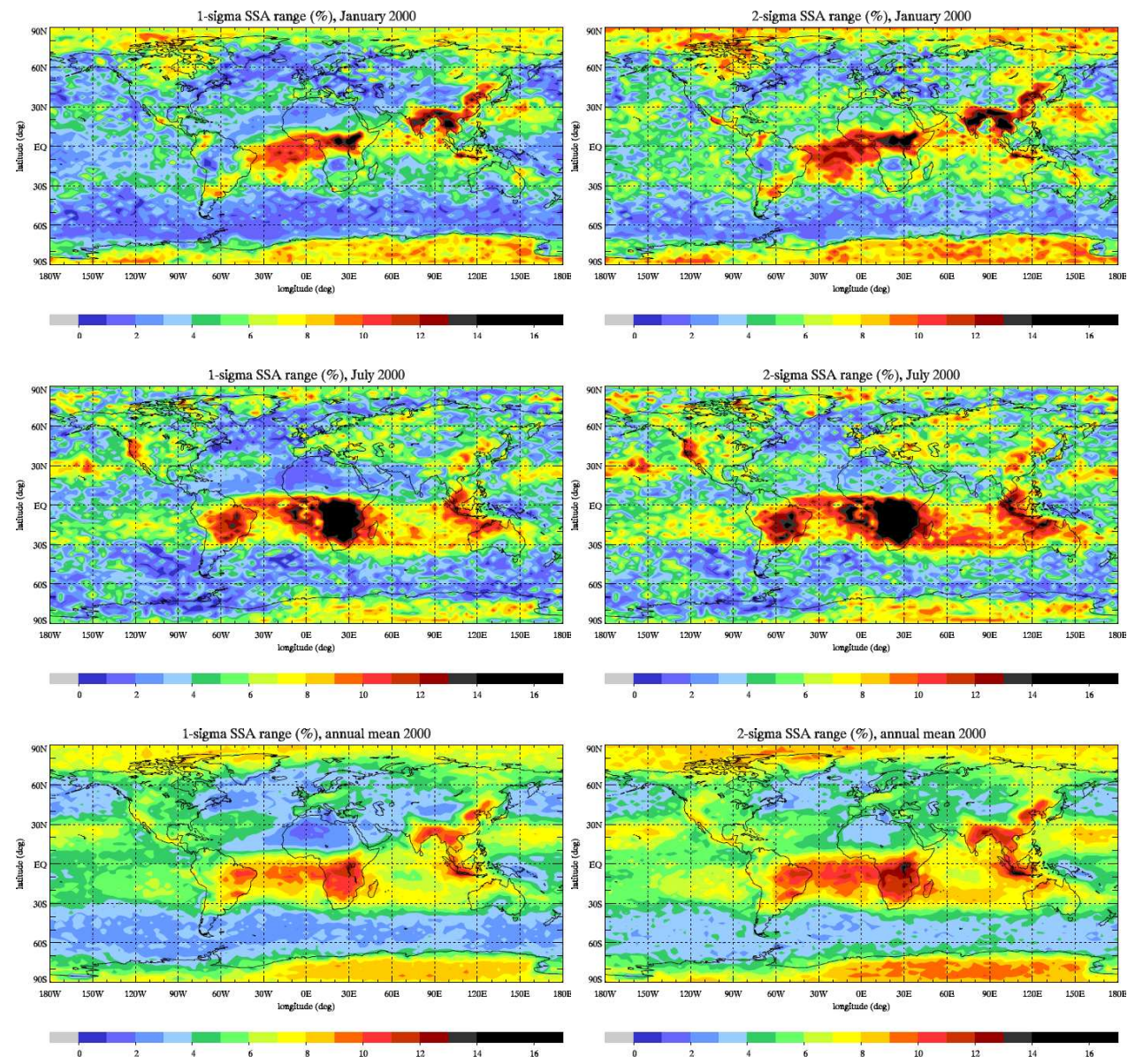

Fig. 10. Spatial variability of the $1 \sigma$ (left) and $2 \sigma$ (right) PDF SSA uncertainty range from all simulations described in Sect. 2.3 for January (top), July (medium) and annual mean (bottom).

\section{ACPD}

8, 16027-16059, 2008

Global error maps of aerosol optical properties

K. Tsigaridis et al.

Title Page

\begin{tabular}{c|c}
\hline Abstract & Introduction \\
\hline Conclusions & References \\
\hline Tables & Figures \\
\hline I & \\
\hline 4 & Close \\
\hline Back & \\
\hline Full Screen / Esc
\end{tabular}

Printer-friendly Version

Interactive Discussion 